\title{
Large deformation of an arc-Miura structure under quasi-static load
}

\author{
X.M. Xianga,b, G. Lu ${ }^{\mathrm{a} *}$, D. Ruan ${ }^{\mathrm{a}}$, Z. You ${ }^{\mathrm{c}}$, M. Zolghadr ${ }^{\mathrm{a}}$ \\ ${ }^{a}$ Faculty of Science, Engineering and Technology, Swinburne University of Technology, Hawthorn, Vic \\ 3122, Australia \\ ${ }^{b}$ Tianjin Key Laboratory of Civil Structure Protection and Reinforcement, Tianjin Chengjian University, \\ Tianjin 300384, China \\ ${ }^{c}$ Department of Engineering Science, University of Oxford, Parks Road, Oxford, OX1 3PJ, UK
}

\begin{abstract}
Miura-Ori based foldcores have been regarded as a potential substitute for conventional honeycomb cores due to many advantages, such as open structure and continuous manufacturing process. Arc-Miura foldcore is one of the Miura-derivative cores which does not have curvature limitations. In this research, the arc-Miura specimens were successfully manufactured using a stamping process and tested under a quasi-static out-of-plane compressive load. An explicit finite element analysis (FEA) of arc-Miura models was developed and validated with the experimental results. Furthermore, a parametric study of arcMiura models subjected to quasi-static out-of-plane compression was performed, through which the relationships between the mechanical properties and the geometric parameters were established. Finally, the mechanical properties of arc-Miura models and corresponding monolithic arches were compared. It was shown that arc-Miura patterns perform better than the corresponding monolithic arches in terms of force and energy absorption.
\end{abstract}

Keywords: Arc-Miura; Monolithic arch; Quasi-static compression; Parametric study.

*Corresponding author. Email: glu@swin.edu.au 


\section{Introduction}

Origami foldcores were proposed during the late 1990's which are basically constructed by folding a sheet using an origami pattern. Origami-inspired structures offer many advantages such as foldability and deployability. These features enable the structure to be compactly stowed in a relatively small package and have good structural performance in the deployed form. For military applications, origami-inspired deployable shelters offer important advantages as they require a very small space in a folded form during transportation $[1,2]$.

One of the most common patterns to make origami foldcores is known as Miura pattern, in which the foldcore is fabricated by folding the sheet along a pattern with straight and zigzag creases [3]. Miura-based origami foldcores possess many useful characteristics, such as rigid foldability, and therefore they have been used in engineering, architectural and design applications. Deformation of Miura pattern foldcores is completely realized by the folding/ unfolding at the creases and does not involve any deformation of the rigid faces [4]. Due to this characteristic, Miura-based origami foldcores can be manufactured easily from sheet materials such as plastics, papers, metals or composites $[5,6]$. Parametrisations have been established to investigate the relationships between crease pattern, volumetric, and kinematic parameters [79].

Mechanical properties of origami patterns have been widely investigated. Honeycomb core has better performance in compression, while flat Miura-based folded cores have comparable or even better performance in the shear and bending cases [10]. Experimental and numerical studies of curved-crease and indented foldcores under quasi-static out-of-plane loads have been conducted by Gattas and You [11, 12]. They found that these modified foldcores have significantly higher energy-absorption capability than straight-crease foldcores. Kirigamiinspired folded core structures were also investigated by means of experiment and numerical simulation by the same research group [13]. The diamond cube strip core offered a much higher increase in average force compared with the best-performing curved-crease and the standard Miura-type foldcore [13]. 
Out-of-plane compression, three-point bending and in-plane compression tests on Elvaloy Miura-ori patterned sheet were carried out by Liu et al. [14]. Based on their simulation results, the deformation patterns and the energy absorption capacity were investigated. Experimental and numerical studies on thermoplastic foldcore (PET and PEEK foldcore) were studied and the result showed that thermoplastic foldcore had comparable or even better energy absorption performances than the aramid one [15].

Research was conducted by numerical simulation and experiment on the axial crushing performance of thin-walled tubes with origami patterns in terms of initial peak force and energy absorption [16, 17]. Other origami structures, e.g., the unit cell with two zigzag strips surrounding a hole with a parallelogram shape [18] and cylindrical foldcore [19], have also been investigated using FEA method. Theoretical analysis of the structural mechanics of folded origami were also analyzed associated with the expansion kinematics of the foldcores [20,21]. Mechanical properties of both periodic and non-periodic origami patterns were studied theoretically by Lv et al. [22], and they found both negative and positive Poisson's ratios of Miura-ori structures. Origami structures were investigated as the core of sandwich structures, and they were found to improve shell bending stiffness and higher strength/weight ratios [23, 24].

Although many aspects of the mechanical behaviours of flat origami-based foldcores have been studied widely in recent years, very limited studies have been conducted on curved Miura-ori structures, which could be used as the foldcores of curved sandwich panels. In this paper, large deformation of arc-Miura structure has been investigated. Two boundary conditions are considered: free ends and clamped ends. Quasi-static out-of-plane compression experiments are conducted first, followed by detailed finite element analyses. A parametric study is conducted to observe the influences of geometric parameters on mechanical performance.

\section{Geometry of arc-Miura pattern}

\subsection{Parameters of the arc-Miura pattern}


The Miura pattern is achieved by repeating a unit cell geometry along two axes on the same plane. The unit cell geometry consists of four identical parallelograms defined by three parameters, $a, b$ and $\phi$ (Fig. 1). Miura foldcore is produced by folding a sheet with the Miura pattern along its straight and zigzag creases. The solid and dashed lines denote the mountain and valley creases respectively. The arc-Miura pattern is one of the first-level derivatives of Miura patterns, which possesses the characteristics of developability, flat-foldability, rigidfoldability and tessellation similar to the Miura pattern. The term "first level derivative" signifies that the geometry is obtained by modifying only one characteristic of the Miura pattern, i.e. crease alignment. Fig. 2 illustrates the arc-Miura pattern derived from the Miura pattern by altering the alignment of zigzag creases. The red dashed line is the altered zigzag crease in comparison with Fig. 1. The solid and dashed lines also denote the mountain and valley creases respectively.

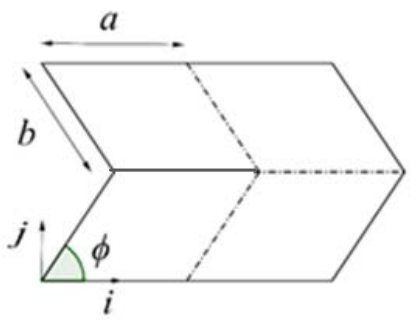

a) Crease pattern of a Miura unit cell

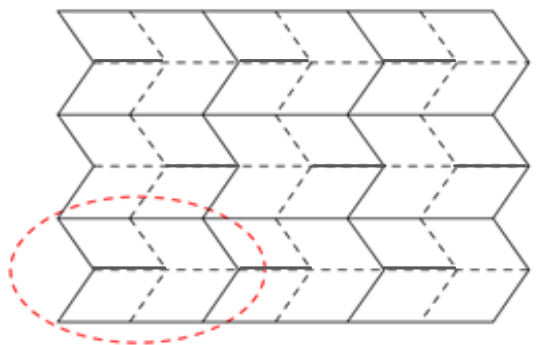

b) Miura crease pattern

Fig. 1 Flat Miura pattern.

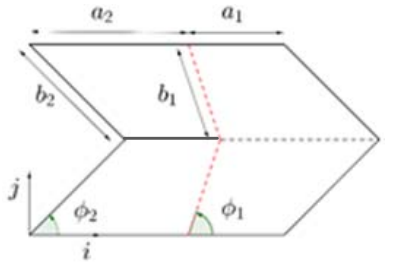

a) Arc Miura unit cell

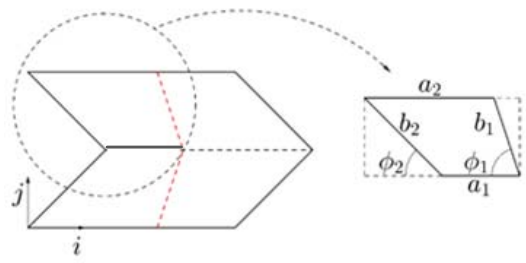

b)Arc-Miura unit cell trapezoid

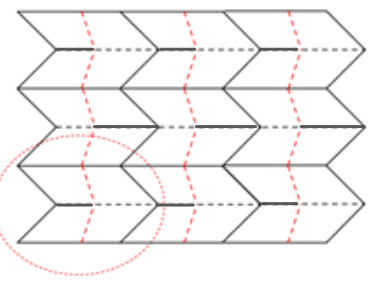

c) Arc-Miura crease pattern

Fig. 2 Arc-Miura pattern. 


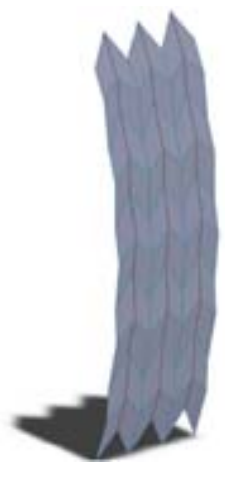

a)

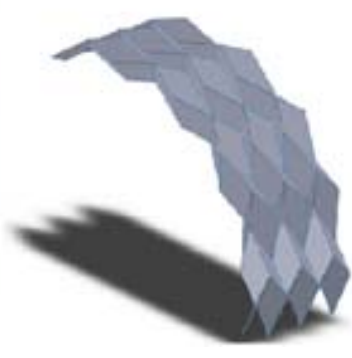

b)

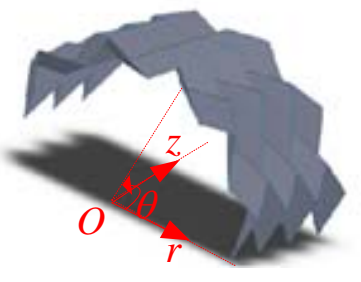

c)

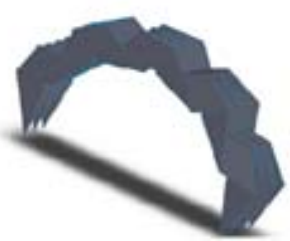

d)

Fig. 3 Arc-Miura pattern folding states.

The zigzag creases in Fig. 2 alter the geometry of the arc-Miura from the Miura pattern. Fig. 3 demonstrates the folding stages of the arc-Miura pattern. A cylindrical coordinate system was built shown in Fig. 3(c). Coordinates $r$ and $\theta$ define the radius and the fold angle of the arcMiura, and coordinate $z$ is in the width direction. The arc-Miura unit cell is formed from four identical trapezoids (Fig. 2(b)). This alteration in the Miura pattern introduces a set of different parameters $a_{1}, a_{2}, b_{1}, b_{2}, \phi_{1}$ and $\phi_{2}$, with the requirement that $a_{1}<a_{2}, b_{1}<b_{2}$ and $\phi_{2}<\phi_{1}<90^{\circ}$. Unlike the flat Miura pattern, the crease pattern parameters in the arc-Miura unit cell are not independent of each other. Eqs. (1) and (2) can be obtained by considering an arc-Miura unit cell trapezoid (see Fig. 2(b)).

$$
\begin{gathered}
b_{1} \sin \phi_{1}=b_{2} \sin \phi_{2} \\
b_{1} \cos \phi_{1}+a_{2}=b_{2} \cos \phi_{2}+a_{1}
\end{gathered}
$$

Gattas et al. [25] presented a parametric model to define the geometry of the arc-Miura pattern. Fig. 4 illustrates the configuration variables and $(r-\theta)$ projection of an arc-Miura pattern with similar variable names defined by them [25]. $\theta_{A}, \theta_{V Z}$ and $\theta_{M Z}$ are the dihedral angles, while $\eta_{V A}$ , $\eta_{V Z}, \eta_{M A}$ and $\eta_{M Z}$ are the edge angles (see Fig. 4(a)). Furthermore, Eqs. (1) to (12) express the relation between all parameters of the arc-Miura parametric model introduced in Ref. [25]. 


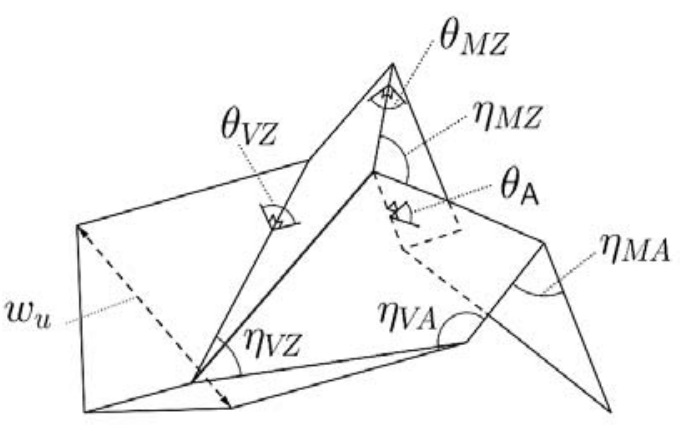

a) Configuration variables

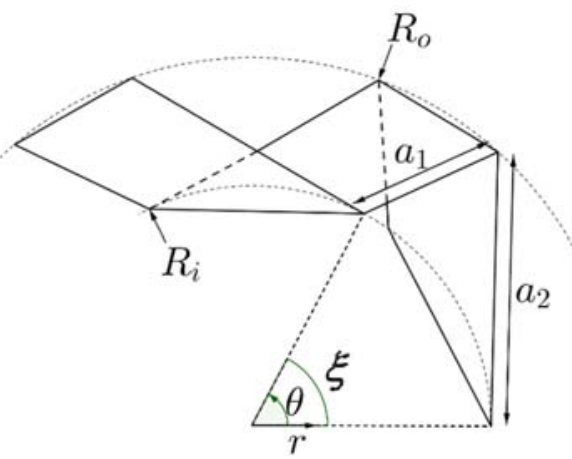

b) $(r-\theta)$ projection

Fig. 4 Arc-Miura geometric parameters.

$$
\begin{gathered}
\left(1+\cos \eta_{M Z}\right)\left(1-\cos \eta_{M A}\right)=4 \cos ^{2}\left(\phi_{1}\right) \\
\left(1+\cos \eta_{V Z}\right)\left(1-\cos \eta_{V A}\right)=4 \cos ^{2}\left(\phi_{2}\right) \\
\cos \eta_{M A}=\sin ^{2} \phi_{1} \cos \theta_{M Z}-\cos ^{2} \phi_{1} \\
\cos \eta_{V A}=\sin ^{2} \phi_{2} \cos \theta_{V Z}-\cos ^{2} \phi_{2} \\
\cos \eta_{M Z}=\sin ^{2} \phi_{1} \cos \theta_{A}+\cos ^{2} \phi_{1} \\
\cos \eta_{V Z}=\sin ^{2} \phi_{2} \cos \theta_{A}+\cos ^{2} \phi_{2} \\
\xi=\eta_{V A}-\eta_{M A} \\
R_{i}^{2}=\frac{a_{1}^{2}+a_{2}^{2}-2 a_{1} a_{2} \cos \eta_{M A}}{2(1-\cos \xi)} \\
R_{o}^{2}=\frac{a_{1}^{2}+a_{2}^{2}-2 a_{1} a_{2} \cos \eta_{V A}}{2(1-\cos \xi)} \\
w_{u}=2 b_{1} \sin \left(\eta_{M Z} / 2\right)=2 b_{2} \sin \left(\eta_{V Z} / 2\right)
\end{gathered}
$$

Eqs. (1) to (12) are sufficient to determine the folded geometry of an arc-Miura pattern regardless of which five geometrical parameters are chosen as the inputs. In this research, an inverse design method has been used to re-formulate Eqs. (1) to (12) in order to facilitate calculation of the unit cell geometrical parameters of the arc-Miura pattern with constrained volumetric parameters, i.e. the inner radius $\left(R_{i}\right)$, outer radius $\left(R_{o}\right)$, fold angle $(\xi)$ and unit cell 
width $\left(w_{u}\right)$. Five inputs are required in order to calculate the other twelve parameters. In this study, these five parameters were chosen to be the four aforementioned volumetric parameters $\left(R_{i}, R_{o}, \xi\right.$ and $\left.w_{u}\right)$, as well as one crease pattern parameter i.e. $a_{1}$. It should be noted that due to the geometrical constraints, $a_{1}$ cannot be assigned any random number unless the number is between two extreme values. These extreme values for $a_{1}$ are determined by the volumetric parameters, $R_{i}, R_{o}$, and $\xi$. Fig. 5 illustrates the extreme positions for both $a_{1}$ and $a_{2}$. The position of the joint where the $a_{1}$ and $a_{2}$ lines cross each other on the outer curve must remain between points B and C. Eqs. (13) and (14) define the conditions for $a_{1}$ and $a_{2}$ implied in Fig. 5.

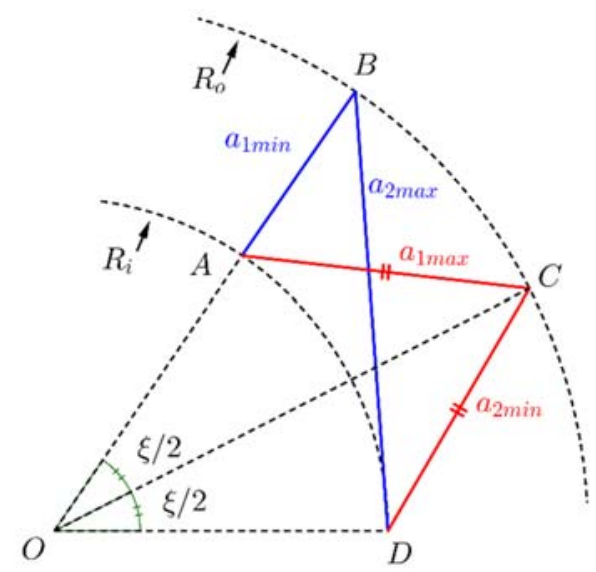

Fig. $5 \quad a_{1}$ and $a_{2}$ at their maximum and minimum value positions.

$$
\begin{gathered}
R_{o}-R_{i}<a_{1}<\sqrt{R_{i}^{2}+R_{o}^{2}-2 R_{i} R_{o} \cos (\xi / 2)} \\
\sqrt{R_{i}^{2}+R_{o}^{2}-2 R_{i} R_{o} \cos (\xi / 2)}<a_{2}<\sqrt{R_{i}^{2}+R_{o}^{2}-2 R_{i} R_{o} \cos \xi}
\end{gathered}
$$

The parametric model was developed using SolidWorks software. The parameters $R_{i}, R_{o}, \xi$, $w_{u}$ and $a_{1}$ were defined as the inputs, and the other parameters were calculated by the software, then the 3D model of a unit cell was developed. Two other parameters required were the number of units in the tangential direction $(m)$, and the number of cells in the lateral direction $(n)$. This 
developed a structure consisting of $m \times n$ cells.

\subsection{Nominal density}

The front view of the arc-Miura structure is shown in Fig. 6. The area of flat surface in each unit (see Fig. 2(a)) is

$$
S=2\left(a_{1}+a_{2}\right) b_{2} \sin \varphi_{2}
$$

The volume occupied by each unit (see Fig. 6) is

$$
V=\pi\left(R_{o}^{2}-R_{i}^{2}\right) \cdot \frac{\xi}{2 \pi} \cdot w_{u}=\frac{\xi}{2}\left(R_{o}^{2}-R_{i}^{2}\right) w_{u}
$$

The norminal density of the arc-Miura is given by

$$
\rho=\frac{\rho_{m} S t}{V}=\frac{4 \rho_{m} t\left(a_{1}+a_{2}\right) b_{2} \sin \varphi_{2}}{\xi\left(R_{o}^{2}-R_{i}^{2}\right) w_{u}}
$$

where $\rho_{m}$ is the density of the base material, $t$ is the thickness of the sheet.

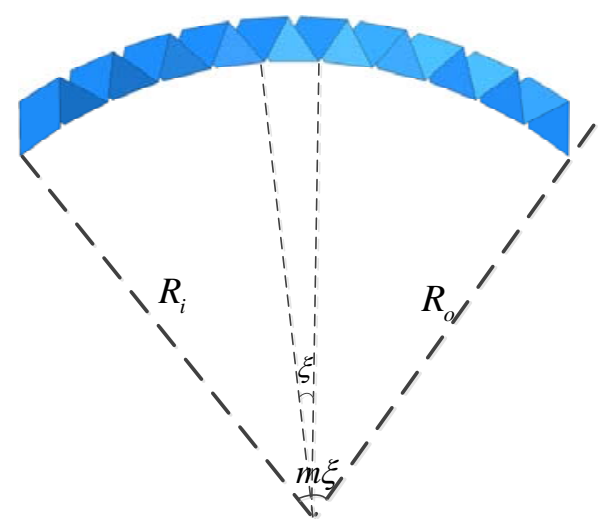

Fig. 6 Dimensions defined in front view.

\section{Experiment and FEA validation}

\subsection{Manufacture of arc-Miura foldcore}

The manufacturing process of foldcores is a challenging task, and should be performed to avoid material and geometrical imperfections. Generally imperfections are categorized into two types: global and local imperfections. Global imperfections include, e.g. irregular cell geometry and 
pre-buckled cell walls. Local imperfections are localised defects within the manufactured specimens such as cracks, pores and wall thickness variations [26].

One of the most common manufacturing methods to fabricate foldcores is stamping a sheet between a male and a female die. Foldcores made of various materials such as aluminium, aramid paper (Kevlar) and fibre reinforced composites were fabricated utilizing this method in many recent researches [26-30]. Another fabrication method is to simply emboss the folding edges on a sheet and folding the sheet manually [27, 30].

Melting the base material and forming the foldcore in moulds is a feasible method of manufacture when the base material melting point is reasonably low. Liu et al. [14] melted palletised Elvaloy $\mathrm{AC} 1820$ at $180^{\circ} \mathrm{C}$ to form a flat sheet. The sheet was then pressed between a pair of male and female moulds at the melting point temperature of $180^{\circ} \mathrm{C}$ to form the foldcore test samples. 3D printing and powder metallurgy have been used to fabricate foldcores. Samples manufactured using this technique do not require significant post-manufacturing processes such as annealing or trimming. Although the precision and accuracy of these methods are better, manufacturing costs are also much higher.

In this research, aluminium alloy sheets (5005H34) were stamped between two dies (see Fig. 7). The lower die was fixed and the upper die moved down under the action of the INSTRON machine indenter. The measured thickness of the aluminium sheet was $0.74 \mathrm{~mm}$. The geometry of the manufactured arc-Miura specimens is shown in Fig. 8 from both front and top views. Geometric parameters of the specimen are listed in Table 1. All the specimens were annealed at $300^{\circ} \mathrm{C}$ using oxy/acetylene gas after the stamping process to remove any residual stresses. 


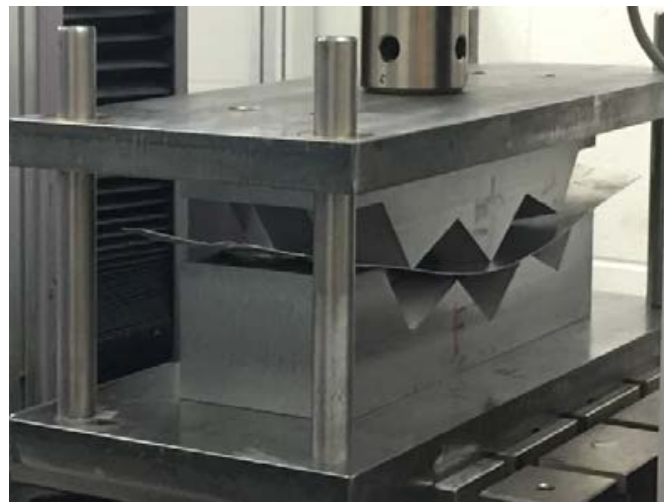

a) during compression

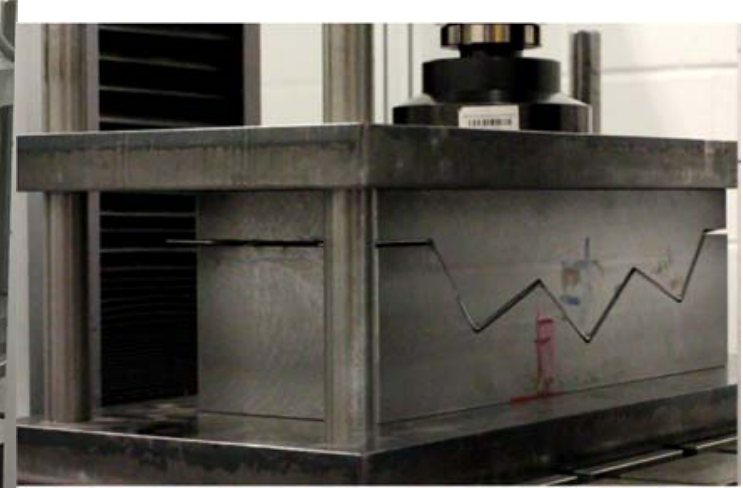

b) after compression

Fig. 7 Manufacturing progress of the arc-Miura specimen: a) during compression; b) after compression.

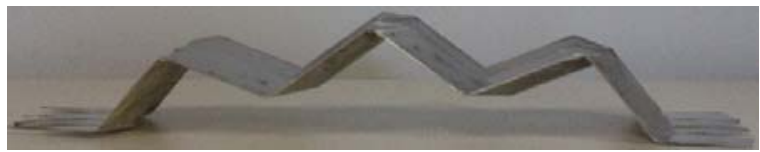

a) front view

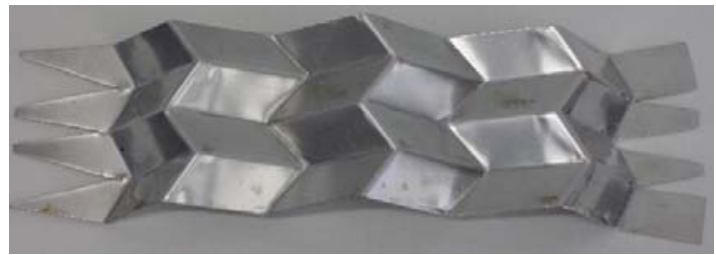

b) top view

Fig. 8 Geometry of the specimen.

Table 1. The parameters of the arc-Miura model in the experiment

\begin{tabular}{lllllll}
\hline$R_{i}(\mathrm{~mm})$ & $R_{o}(\mathrm{~mm})$ & $\xi\left(^{0}\right)$ & $w_{u}(\mathrm{~mm})$ & $a_{1}(\mathrm{~mm})$ & $m$ & $n$ \\
\hline 360 & 390 & 15 & 50 & 55 & 3 & 2
\end{tabular}

\subsection{Quasi-static compressive experiment and result}

The specimens had two different boundary conditions: free ends and clamped ends (see Fig. 9). Tensile tests were conducted on standard dog-bone specimens using a MTS machine, and the engineering tensile stress-strain curve of this aluminum alloy material was obtained (shown in Fig. 10).

Quasi-static compressive tests at a constant speed of $3 \mathrm{~mm} / \mathrm{min}$ were conducted on the arc-Miura specimens by using an INSTRON machine (see Fig. 11). Fig. 11 shows the deformation progress of the specimens with both free ends and clamped ends. Force - displacement curves of the two tests are shown in Fig. 12. It was found that there were two points (1) and (2) in Fig. 
12) where the force increased suddenly. Point (1) corresponded to the moment when the upper plate touched the top two creases, while point (2) corresponded to the moment when the bottom two creases touched the base plate (see Fig. 11).

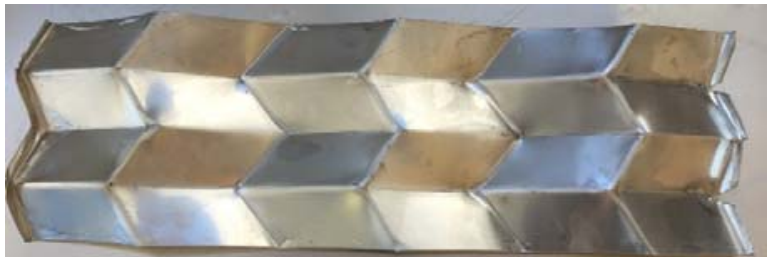

a) free ends

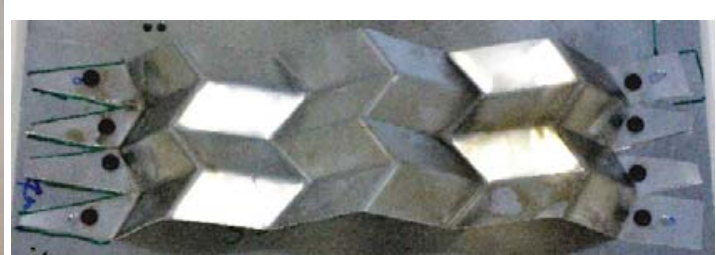

b) clamped ends

Fig. 9 Specimens with two different boundary conditions used in experiment.

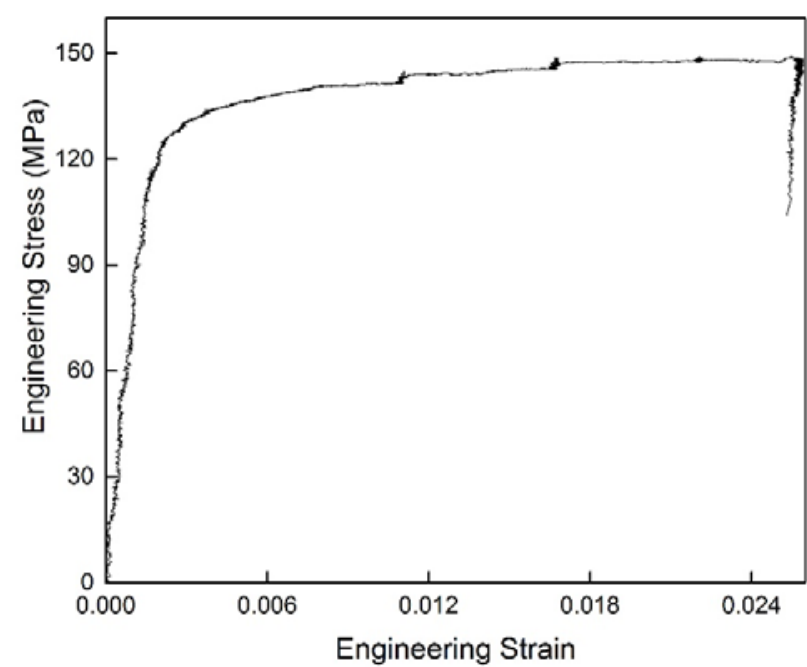

Fig. 10 Engineering stress-strain curve of the specimen material. 


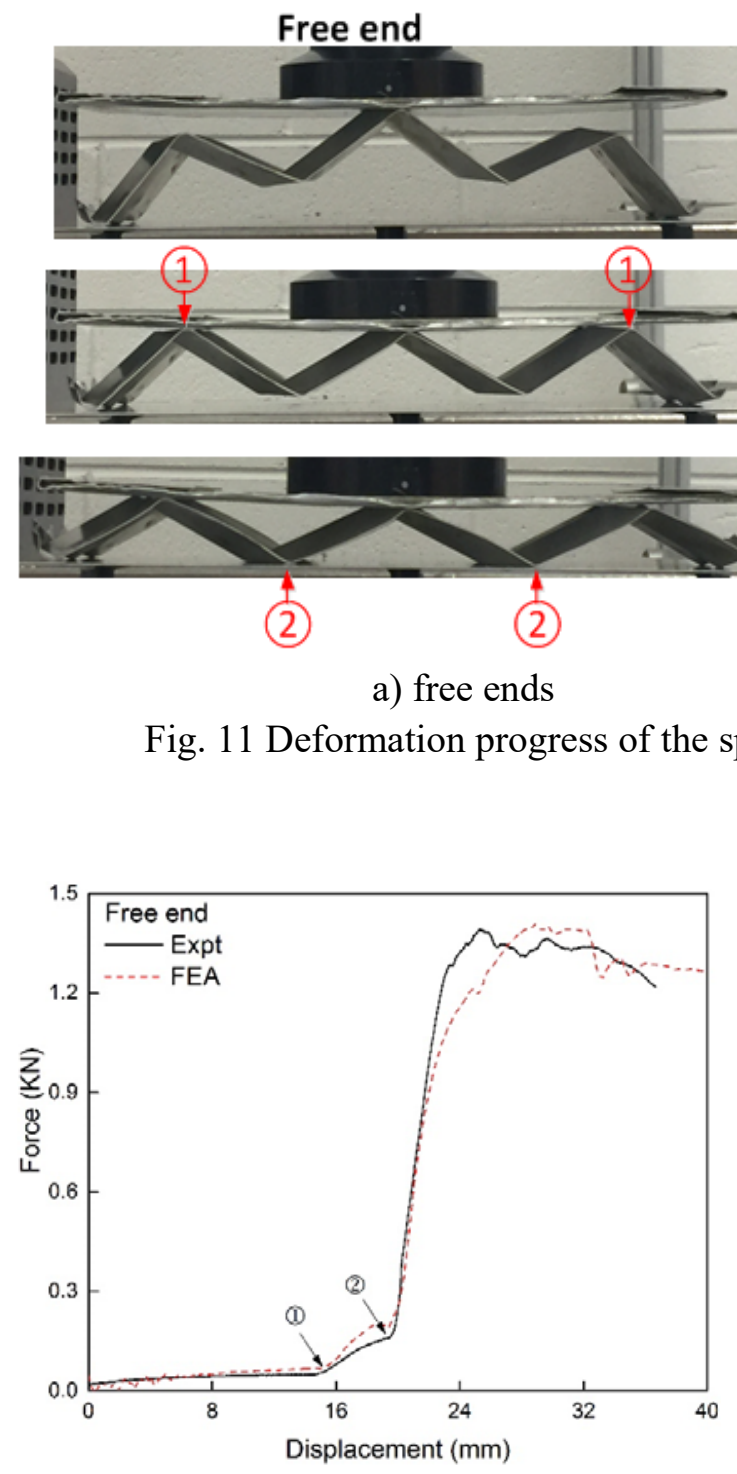

a) free ends
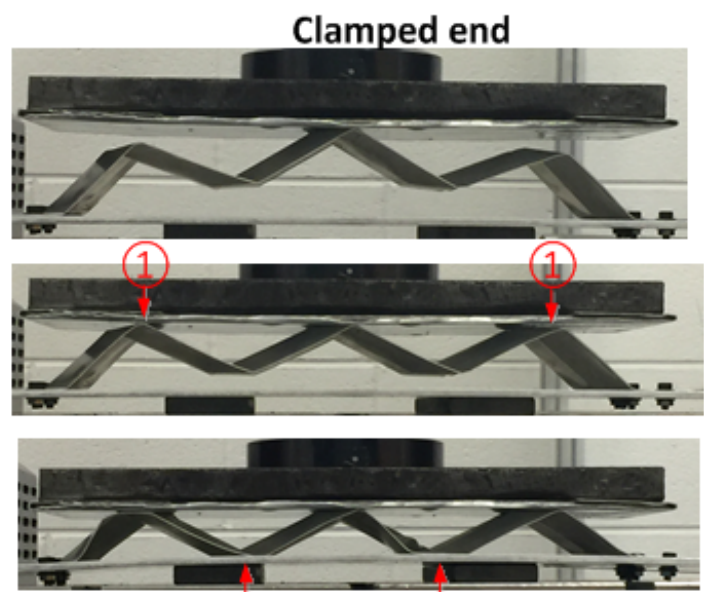

(2)
(2)

b) clamped ends

Fig. 11 Deformation progress of the specimens: a) free ends; b) clamped ends.

Fig. 12 Comparisons of experimental and FEA results of the specimens with two different boundary conditions: a) free ends; b) clamped ends.

\subsection{FEA validation}

Finite element analysis was conducted by using ABAQUS. The elements of the models were linear quad element, type S4R and the mesh size was $2 \mathrm{~mm}$. The true stress versus true plastic strain curve used in the FEA was derived from the engineering stress-strain curve measured in the tensile tests (see Fig. 10). The upper and the base plates were modelled as rigid bodies and the friction coefficient was set as 0.12 . The simulation results in terms of force-displacement curves for both two boundary conditions match well with the experimental results (see Fig. 12). 
Fig. 13 shows that the deformation of the clamped specimens after unloading in FEA was similar to that in the experiment, and there were two localized folded area across the whole specimen: one located at the middle part; and the other one located at the left side. After the bottom two creases touched the base plate, buckling occurred in the face of the units and then the neighboring units contacted with each other.

a) Experiment

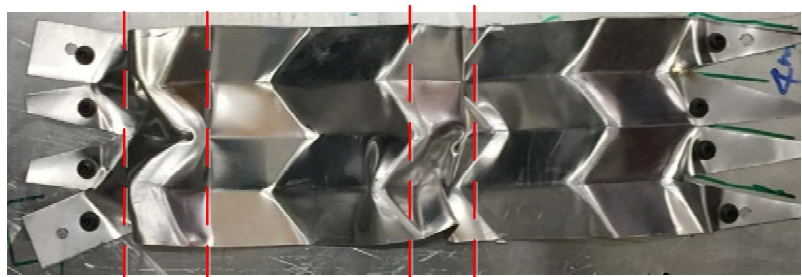

b) FEA

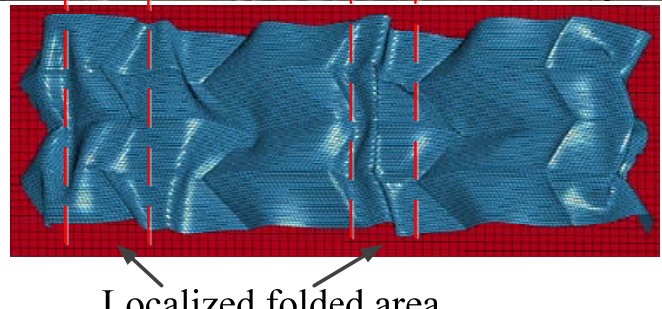

Fig. 13 Deformation for clamped specimen in experiment and corresponding FEA: a) Experiment; b) FEA.

\section{FEA parametric study}

\subsection{Influence of side length $a_{1}$}

The arc-Miura models were determined by volumetric parameters $\left(R_{i}, R_{o}, \xi, w_{u}\right)$, a crease parameter $\left(a_{1}\right)$ and the numbers of units in the tangential and lateral directions ( $m$ and $n$ respectively). Eq. (13) shows that the value of the crease parameter, $a_{1}$, can vary between two extreme values $a_{1 \min }$ and $a_{1 \max }$ shown in Eq.(18) and (19) respectively. Variation of $a_{1}$ causes the value of the other geometrical parameters to change.

$$
\begin{gathered}
a_{1 \min }=R_{o}-R_{i} \\
a_{1 \max }=\sqrt{R_{i}^{2}+R_{o}^{2}-2 R_{i} R_{o} \cos (\xi / 2)}
\end{gathered}
$$


To study the effect of $a_{1}$ on the main variable parameters of the arc-Miura pattern, a model was generated with constant parameters listed in Table 2. Parameter $a_{1}$ was varied, and Table 3 shows that the other crease pattern parameters $\left(a_{2}, b_{1}, b_{2}, \phi_{1}, \phi_{2}\right)$, the lateral dihedral angle $\left(\theta_{A}\right)$ and the total surface area $(S)$ were affected by the value of $a_{1}$. It can be seen that the values of $\phi_{1}, \phi_{2}$ and $\theta_{A}$ increase with the increasing value of $a_{1}$, while $a_{2}, b_{1}, b_{2}$ and $S$ decrease.

Fig. 14 is a snapshot of the arc-Miura models generated based on the increasing values of $a_{1}$. All the geometric parameters are listed in Table 2 and Table 3. It shows that the models with lower $a_{1}$ are more densely packed and have larger surface area. In order to keep all the models with the same mass, the thickness of the shell varies with different values of $a_{1}$, which is also listed in Table 3.

Table 2. The values of the parameters used to generate the arc-Miura model

\begin{tabular}{cccccccc}
\hline$R_{i}(\mathrm{~mm})$ & $R_{o}(\mathrm{~mm})$ & $\xi\left(^{0}\right)$ & $w_{u}(\mathrm{~mm})$ & $a_{1 \min }(\mathrm{mm})$ & $a_{1 \max }(\mathrm{mm})$ & $m$ & $n$ \\
\hline 300 & 330 & 7 & 35 & 30 & 35.6 & 10 & 10
\end{tabular}

Table 3. The main geometric parameters

\begin{tabular}{ccccccccc}
\hline$a_{1}(\mathrm{~mm})$ & $a_{2}(\mathrm{~mm})$ & $b_{1}(\mathrm{~mm})$ & $b_{2}(\mathrm{~mm})$ & $\phi_{1}\left({ }^{0}\right)$ & $\phi_{2}\left({ }^{0}\right)$ & $\theta_{A}\left({ }^{0}\right)$ & $S\left(\mathrm{~mm}^{2}\right)$ & $t(\mathrm{~mm})$ \\
\hline 33.4 & 38.3 & 69.1 & 71.6 & 60.6 & 57.2 & 33.8 & $8.6 \mathrm{e} 5$ & 0.31 \\
33.9 & 37.5 & 51.8 & 53.6 & 61.3 & 57.9 & 45.3 & $6.5 \mathrm{e} 5$ & 0.41 \\
34.5 & 36.8 & 36.2 & 37.3 & 63.3 & 60.1 & 65.4 & $4.6 \mathrm{e} 5$ & 0.58 \\
35.1 & 36.2 & 23.4 & 23.8 & 70.1 & 67.5 & 105.5 & $3.1 \mathrm{e} 5$ & 0.86
\end{tabular}



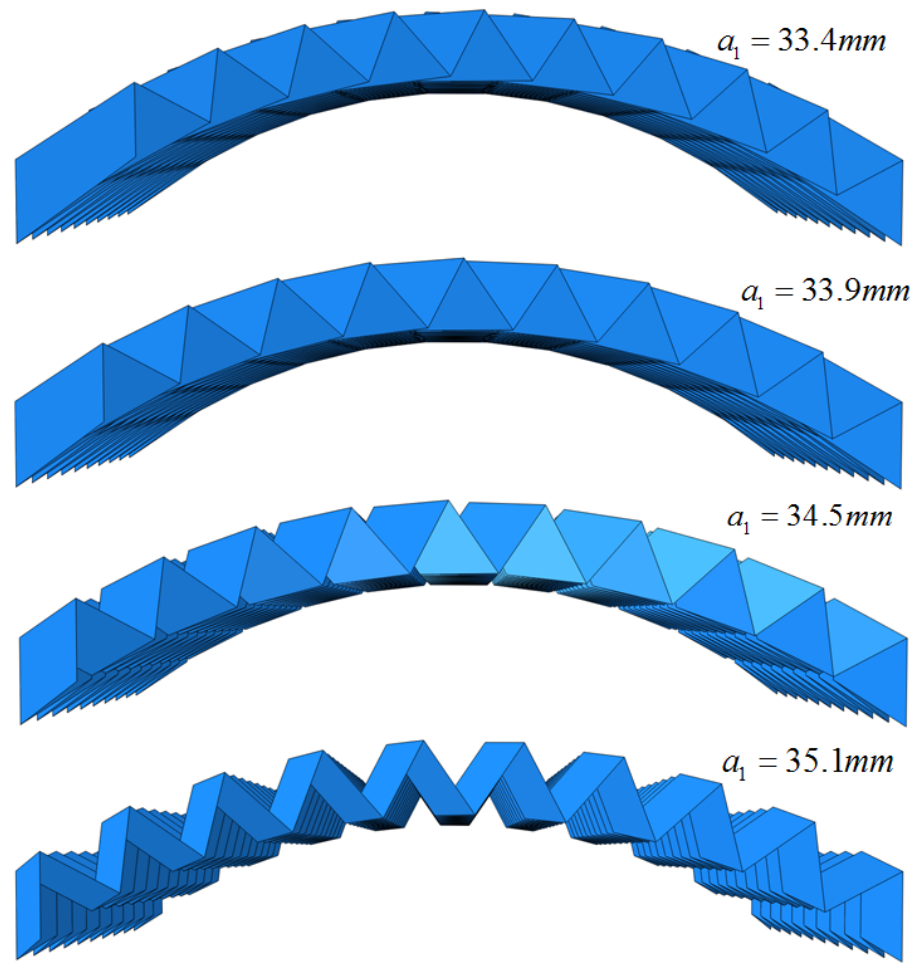

Fig. 14 The arc-Miura models for different values of $a_{1}$. 

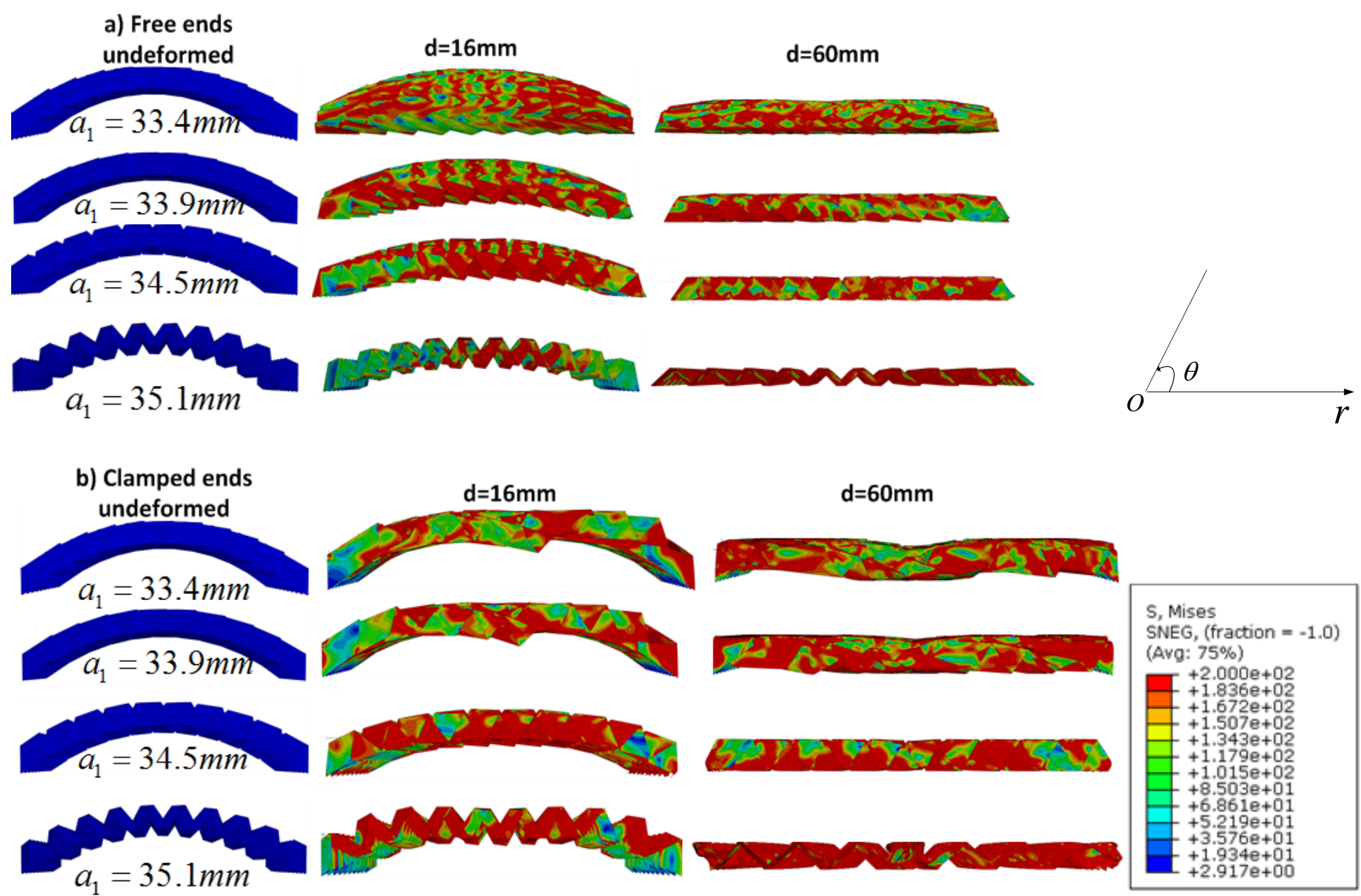

Fig. 15 Front view ( $r-\theta$ plane) of the deformed arc-Miura models for different values of $a_{1}:$ a) free ends; b) clamped ends ( $d$ is the displacement of the top rigid plate $)$. 


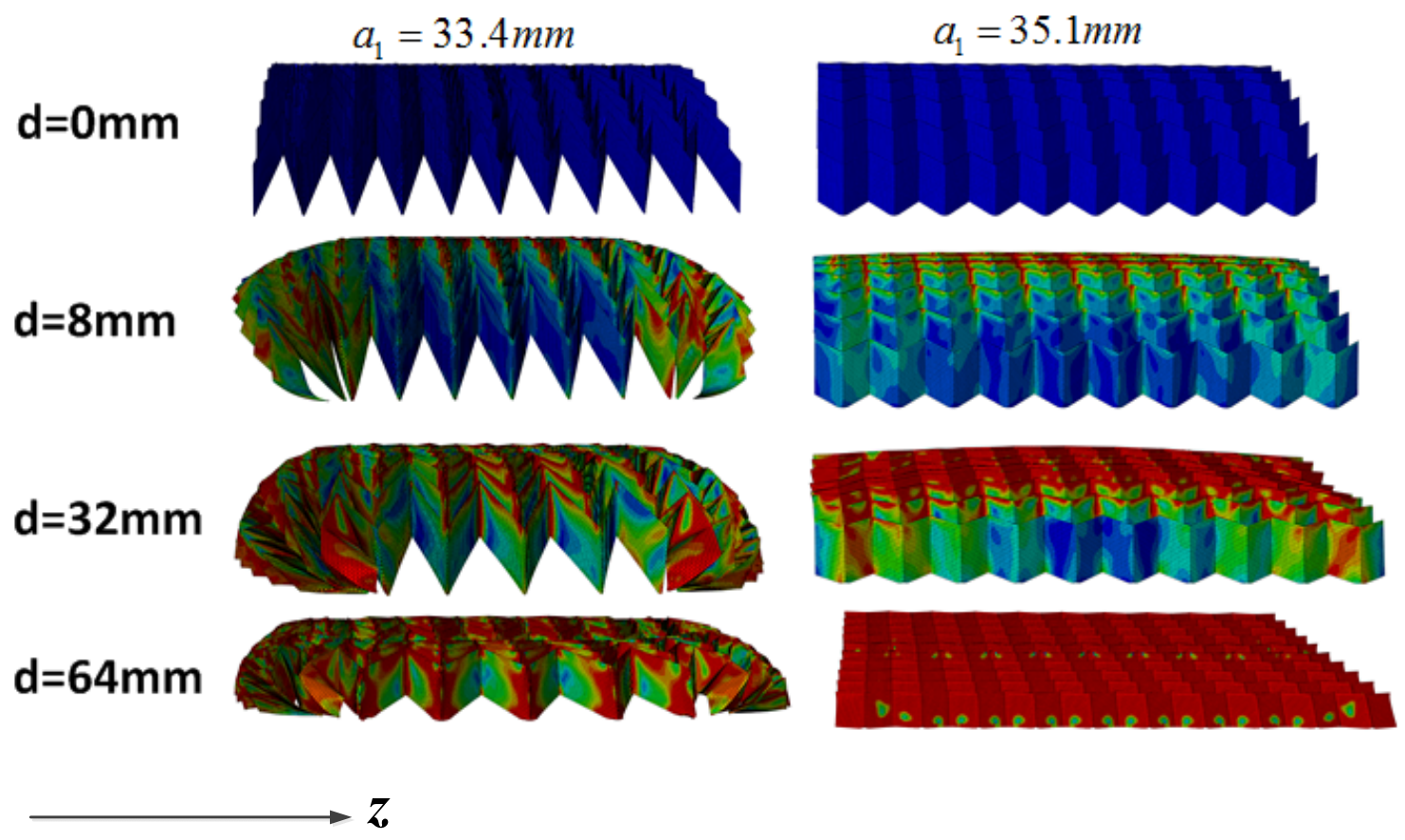

Fig. 16 Side view of the deformed arc-Miura models with free ends.

FEA was conducted on the arc-Miura models using ABAQUS. Mild steel was chosen as the material of the specimens because it is more ductile and economical than the aluminum alloy. An elastic-perfectly-plastic mild steel model was used in our FEA with density $7800 \mathrm{~kg} / \mathrm{m}^{3}$, Young's Modulus 210GPa, and yield stress 200MPa. The specimens were compressed out-ofplane between two rigid plates. The front view of the deformed models for different values of $a_{1}$ with free ends and clamped ends is shown in Fig. 15. For models with free ends, when $a_{1}=33.4 \mathrm{~mm}$ and $33.9 \mathrm{~mm}$, the front view of the deformation seemed like a dome, and it was because the units at the two sides in the lateral direction would slide inwards (see Fig. 16: $a_{1}=33.4 \mathrm{~mm}$ ). However, when $a_{1}=34.5 \mathrm{~mm}$ and $35.1 \mathrm{~mm}$, the movement inwards did not happen (see Fig. 16: $a_{1}=35.1 \mathrm{~mm}$ ). Deformation progress of two neighboring units (clamped ends, $\left.a_{1}=35.1 \mathrm{~mm}\right)$ is shown in Fig. 17. In the early stage of deformation, global deformation took place. In the late stage of deformation, buckling occurred in the faces of the units and then the neighboring units contacted with each other. The force-displacement curves are shown in Fig. 18 for both cases of free ends and clamped ends. The curves are similar to that of a typical cellular structure, such as foam and honeycomb, consisting of an elastic stage, a plateau and a 
densification stage. For both the two boundary conditions, the force increased slightly with the decreasing value of $a_{1}$. The energy absorption by the four models with free ends and clamped ends will be discussed in Section 5.

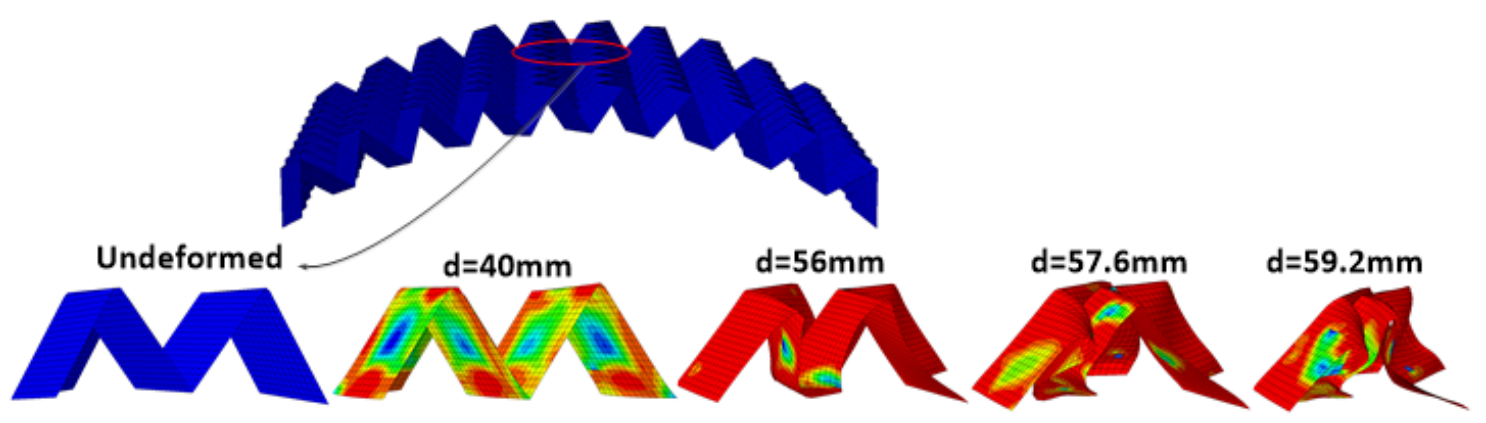

Fig. 17 Deformation progress of two neighboring units (clamped ends, $a_{1}=35.1 \mathrm{~mm}$ )

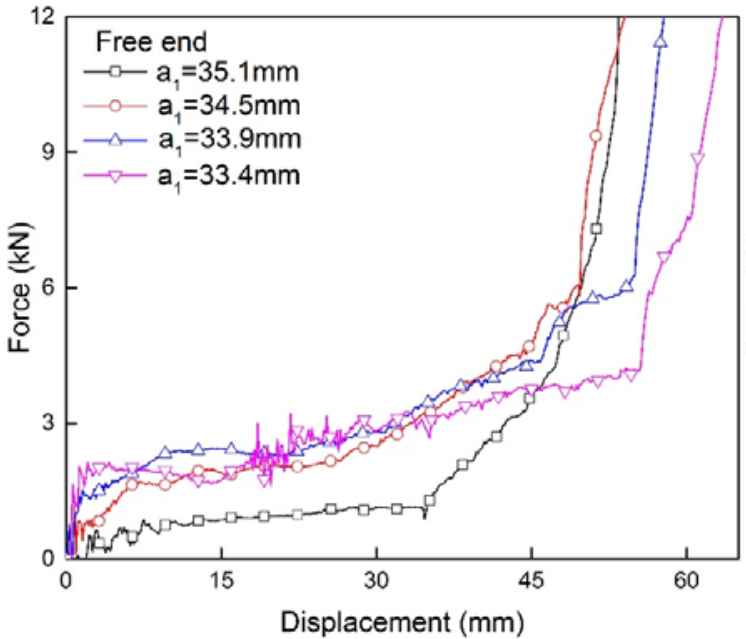

a) free ends

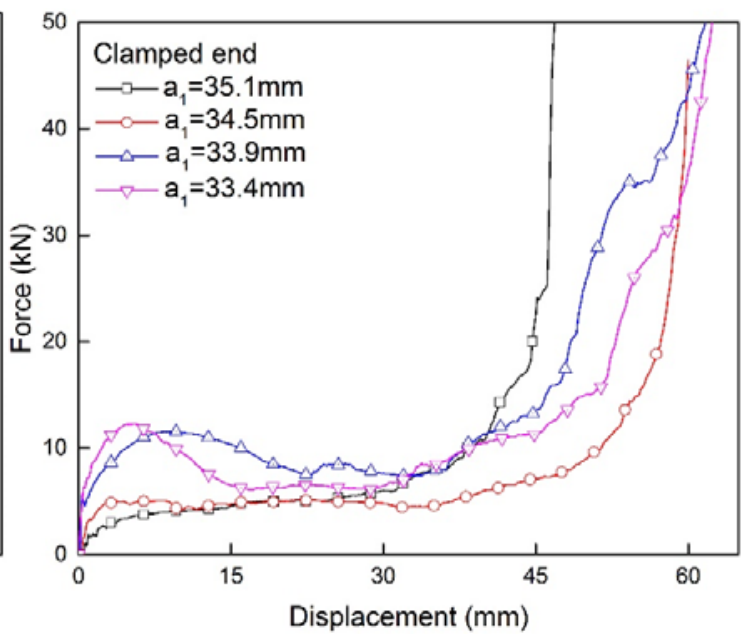

b) clamped ends

Fig. 18 FEA force-displacement curves for both free end and clamped end cases.

\subsection{Influence of the number of cells, $m$}

Models with a constant $a_{1}=34.5 \mathrm{~mm}$ and different $m(10,14,18$ and 22) were generated (see Fig. 19) in order to study the influence of total arc angle $(m \xi)$ on the mechanical property of the arc-Miura. The values of $m \xi$ are $70^{\circ}, 98^{\circ}, 126^{\circ}$ and $154^{\circ}$ for $m=10,14,18$ and 22 respectively (shown in Fig. 19). 


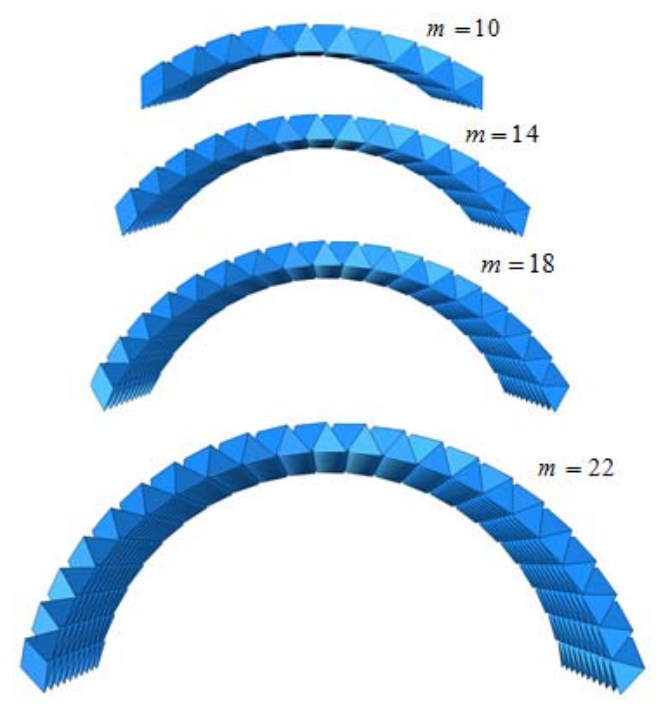

Fig. 19 The arc-Miura models for different numbers of cells, $m$.

For each type of arc-Miura pattern, the corresponding monolithic arch was developed. The radius of the monolithic arch was taken as the average of the outer and inner radius of the arcMiura, $R=\left(R_{o}-R_{i}\right) / 2$. The angle of the monolithic $\operatorname{arch}(2 \gamma)$ is the total folding angle of the arc-Miura $(m \xi)$. The width of the monolithic arch was the same as that of the arc-Miura, $w_{u}=350 \mathrm{~mm}$. The material parameters were the same for the two structures. In order to keep the mass of the monolithic arch the same as that of the corresponding arc-Miura, the thickness $t$ was varied for different monolithic arc models. The parameters of the monolithic arches are listed in Table 4.

Table 4 Parameters of the monolithic arch

\begin{tabular}{ccc}
\hline$R(\mathrm{~mm})$ & $2 \gamma\left(^{0}\right)$ & $t(\mathrm{~mm})$ \\
\hline & 70 & 1.937 \\
315 & 98 & 1.954 \\
& 126 & 1.964 \\
& 154 & 1.967
\end{tabular}

Deformation progress of the arc-Miura and corresponding monolithic arches with both free ends and clamped ends is shown in Fig. 20. The comparison of the two structures will be made in Section 5.

The top view (see Fig. 21) shows that the final deformation of the clamped arc-Miura with a 
total arc angle $70^{\circ}(m=10)$ was different from the other three patterns with "necking" effect at the mid span ( $m=14,18$ and 22). From Fig. 22, we can find that the cells at the middle part would fall down firstly. In the front view (Fig. 20), they seemed like an "M" shape, the same as that for the corresponding monolithic arch. For the model with $m=14$, before the middle cells touched the base plate, only a few cells fell down and there was not enough room for those falling cells to move inwards. However, the height of the model with $m=18$ is larger, and the initial falling cells moved inwards, then their neighboring cells fell down subsequently. Therefore, the "necking" effect is visible for the models with $m>14$.

The force-displacement curves for the two boundary conditions are plotted in Fig. 23. For the case of free ends, the duration time of the plateau increased largely with the increasing value of $m$, while the plateau force decreased. When $m=18$ and $m=22$, the plateau forces were almost the same. For the case of clamped end, the plateau force decreased slightly with the increasing value of $m(m=14,18$ and 22$)$ and they were much higher than that when $m=10$. The energy absorption by the four models with both free ends and clamped ends will also be discussed in Section 5.

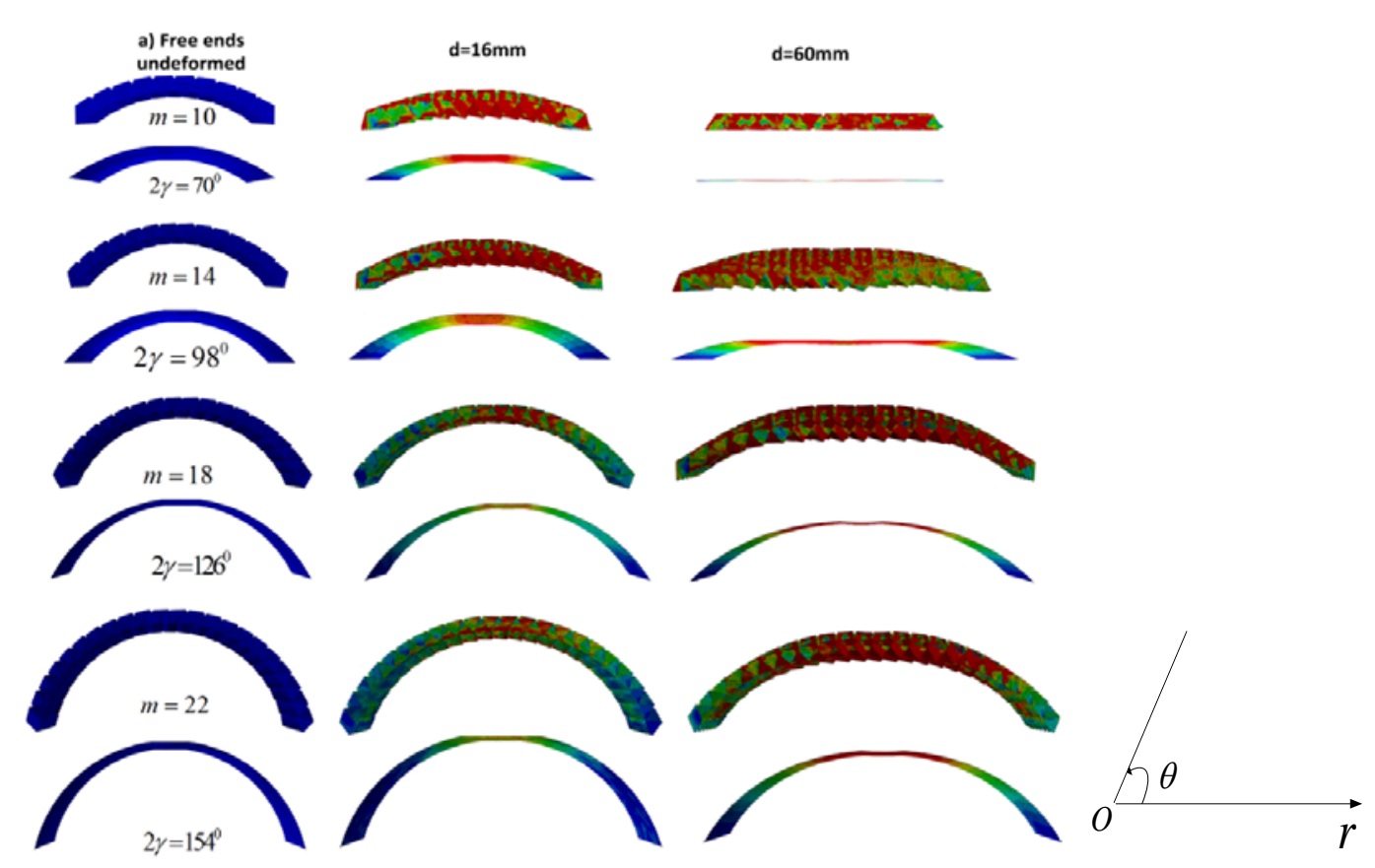




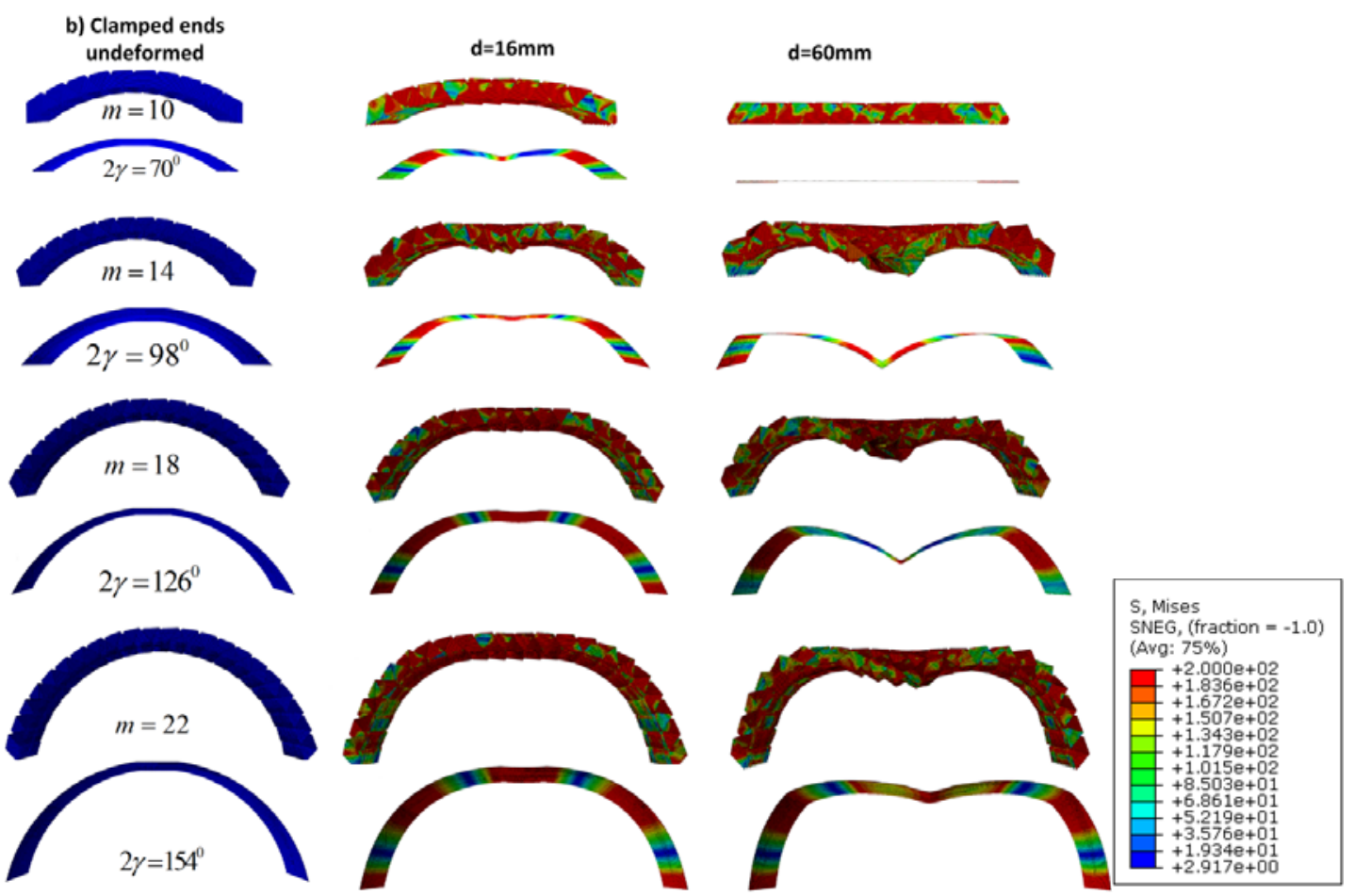

Fig. 20 Front view ( $r-\theta$ plane) of the deformed arc-Miura models and the corresponding monolithic arches with free ends and clamped ends.

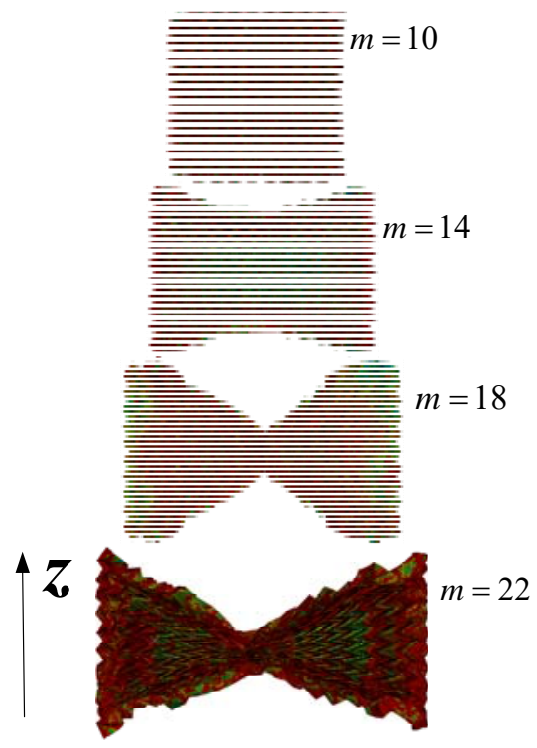

Fig. 21 Top view of the final deformation of the arc-Miura models with clamped ends. 


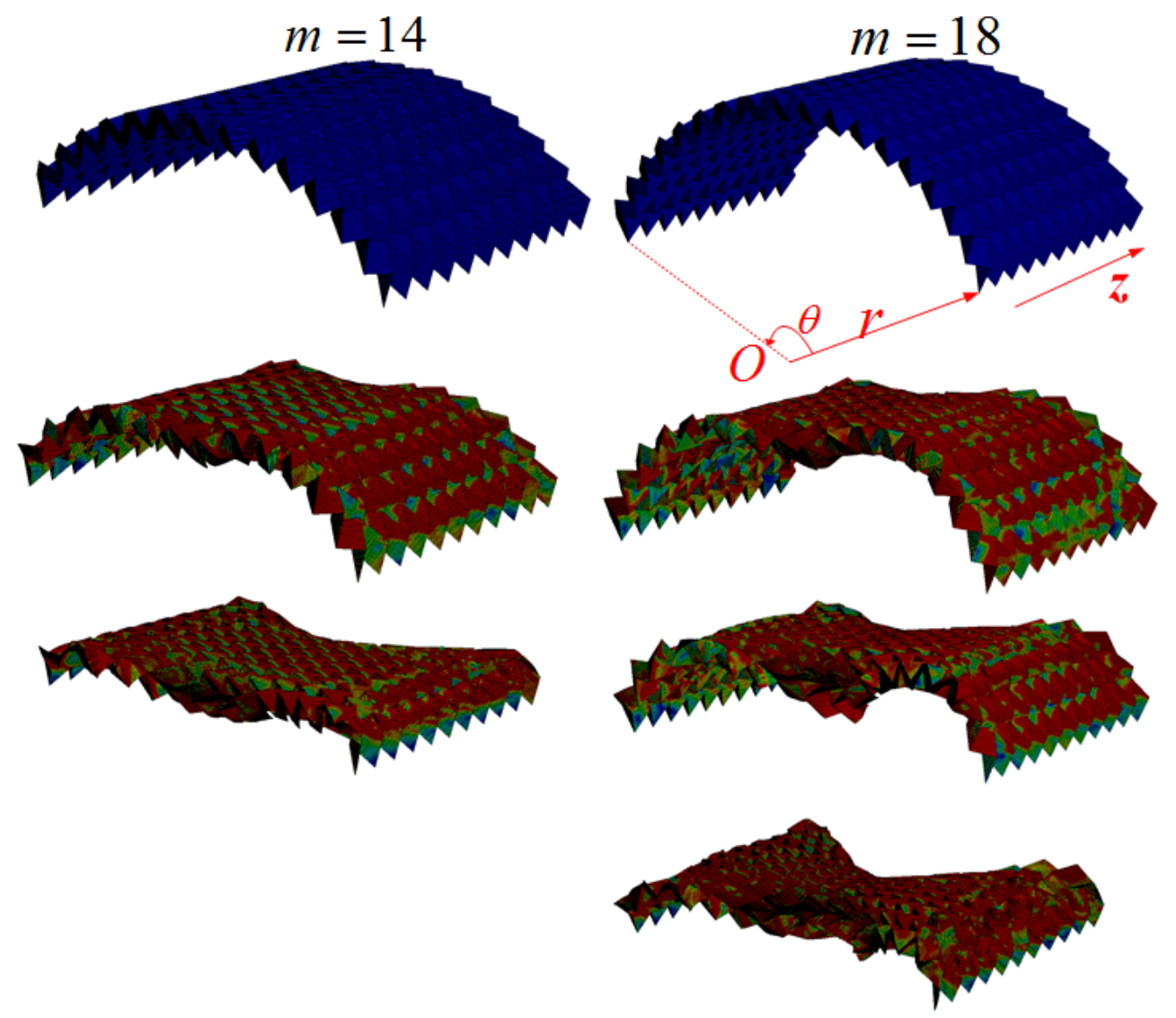

Fig. 22 Comparison of deformation progress of the arc-Miura models with $m=14$ and $m=18$.

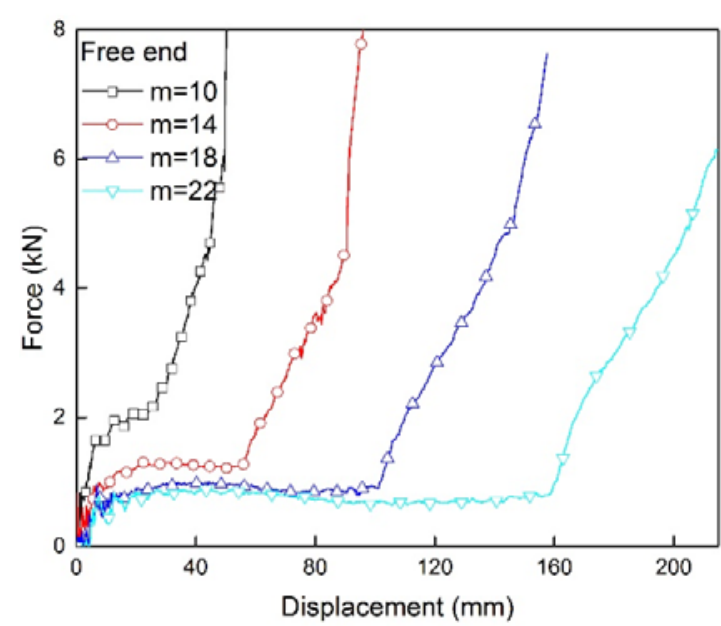

a) free ends

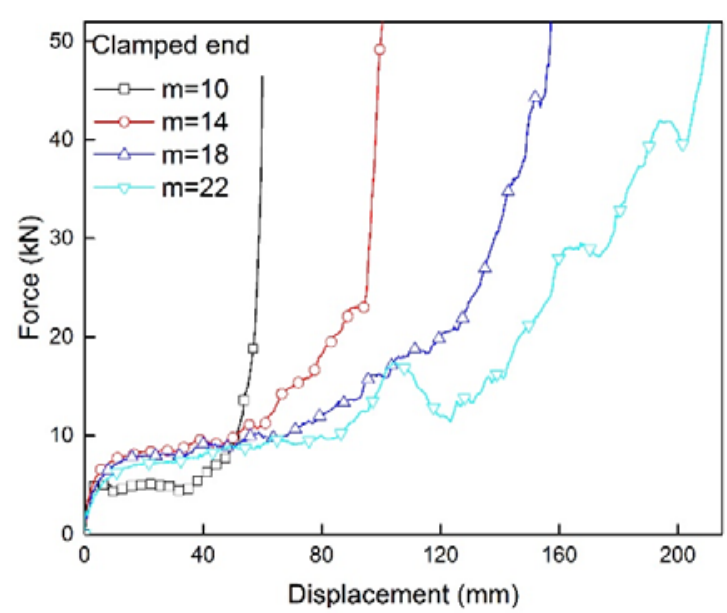

b) clamped ends

Fig. 23 FEA force-displacement curves of the arc-Miura models and the corresponding monolithic arches: a) free ends; b) clamped ends. 


\section{Discussion}

\subsection{Influence of boundary condition}

The effect of the boundary conditions on the mechanical behaviour was investigated. The geometry parameters of the arc-Miura are listed in Table 2 and Table 3 when $a_{1}=34.5 \mathrm{~mm}$. For free ends, the friction coefficient was chosen as $0,0.5,1$, and 1.5 respectively. The corresponding force-displacement curves are plotted in Fig. 24 as well as the forcedisplacement curves for clamped ends. The force increased slightly with increasing friction coefficient. It was found that when the friction coefficient was 0.5 , the force-displacement curve was almost the same as that without friction, which indicates that the friction coefficient had little effect on the mechanical properties of the arc-Miura structure.

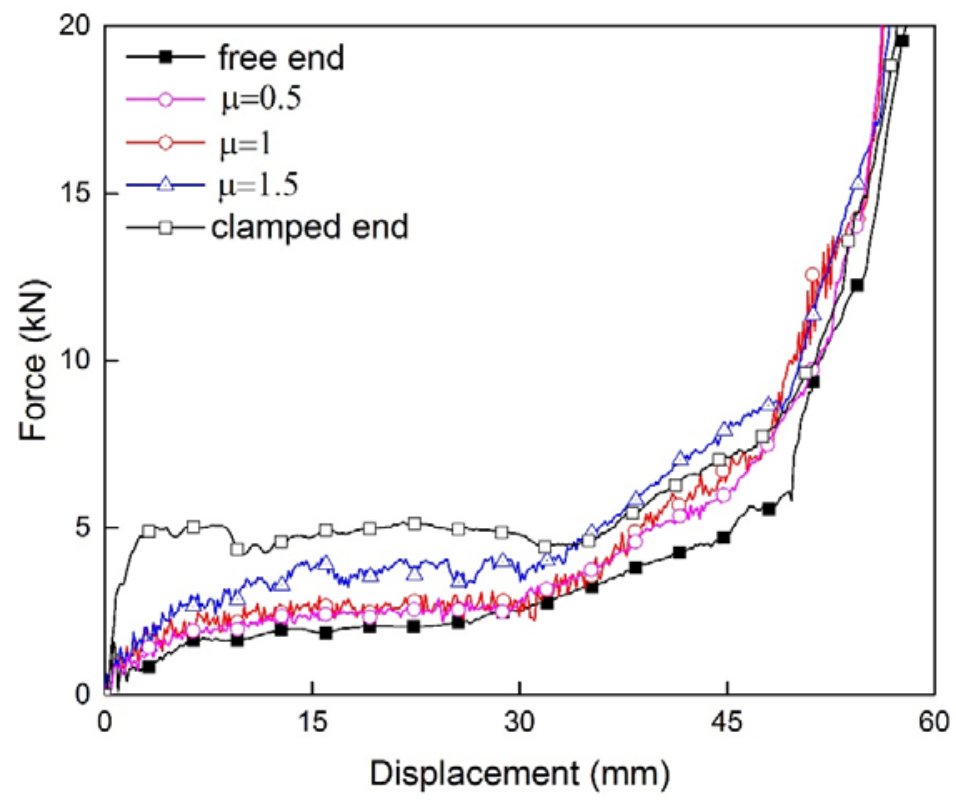

Fig. 24 FEA force-displacement curves for the model with different friction coefficients.

\subsection{Comparison with corresponding monolithic arch}

The deformation progress of the monolithic arch with free ends and clamped ends is shown in Fig. 20 and corresponding force-displacement curves are plotted in Fig. 25. For the case of free ends, the deformation modes were almost the same for the two structures. When $m=10$ and 14 , the out-of-plane force of the arc-Miura was higher than that of monolithic arch, while when 
$m=18$ and 22, the out-of-plane force was almost the same for the two structures. For the case of clamped ends, the monolithic arch had a stationary plastic hinge at midspan, and the hinge point moved downwards until it touched the base plate. The clamped arc-Miura pattern did not have such plastic hinge.

When $m=10$, the final deformation of the arc-Miura pattern did not have the necking effect (see Fig. 21) and its plateau force was almost the same as the corresponding monolithic arch. When the plastic hinge at midspan of the monolithic arch touched the base plate, the force increased dramatically. However, this did not happen for the arc-Miura structure. When $m=14,18$ and 22, the final deformations of the arc-Miura pattern had the necking effect (see Fig. 21) and the force was much higher than that of the corresponding monolithic arch.

The theoretical relationship between the force and displacement for monolithic arch with free ends is illustrated in Appendix-A(a), and the curves are plotted as dashed lines in Fig. 25. The initial collapse load for monolithic arch with clamped ends is shown in Appendix-A(b), and the values are shown as the solid blue lines in Fig. 25. The theoretical results match well with the FEA results (shown in Fig. 25).

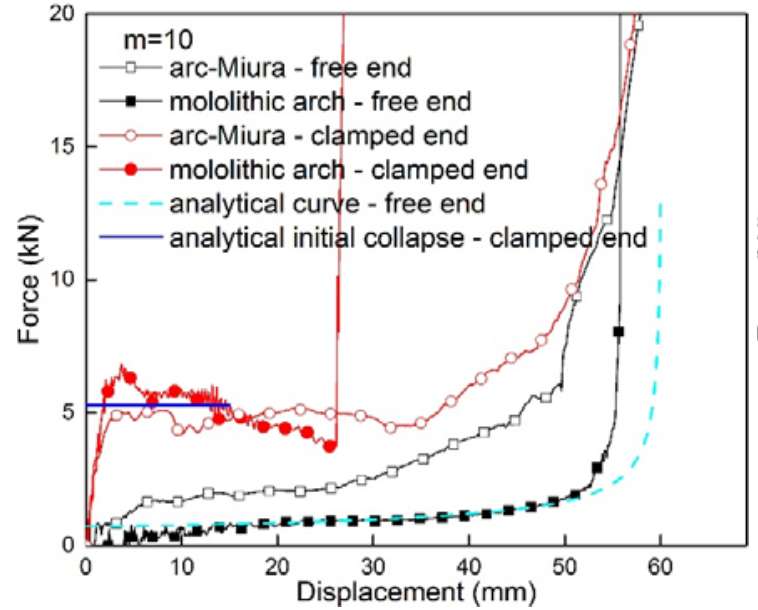

a) $m=10$

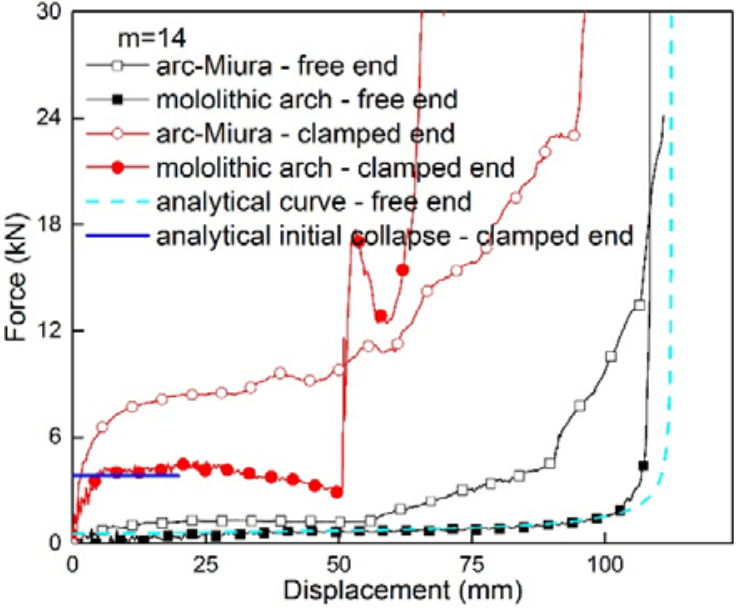

b) $m=14$ 


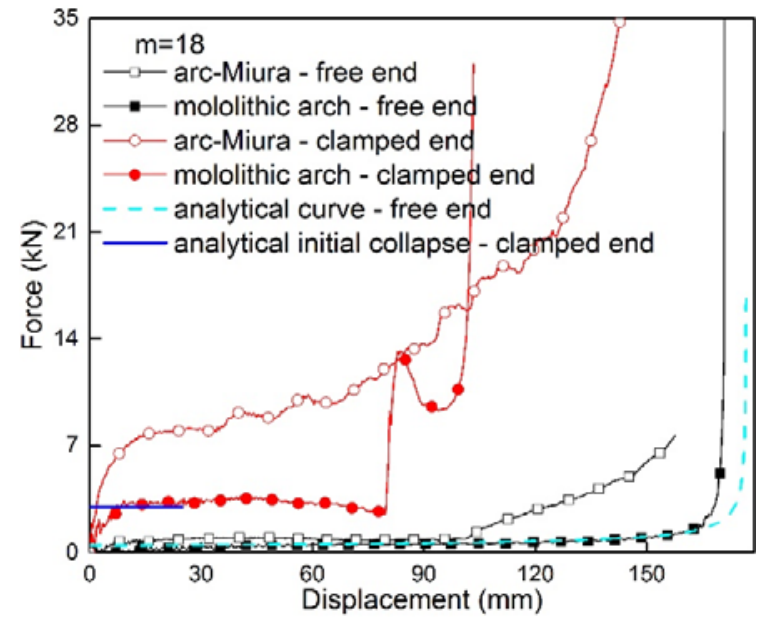

c) $m=18$

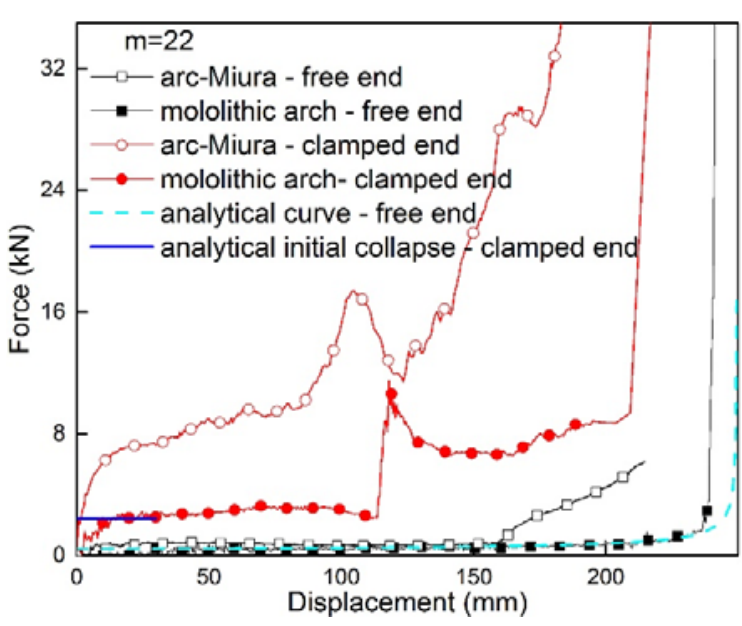

d) $m=22$

Fig. 25 Comparison of the arc-Miura models for various numbers of cells, $m$, and the corresponding monolithic arches: a) $m=10$; b) $m=14$; c) $m=18$; d) $m=22$.

\subsection{Energy absorption}

The energy absorbed by both the arc-Miura and monolithic arch was obtained from the FEA models and is listed in Table 5. $E_{f}$ and $E_{c}$ are the energy absorbed by the specimens with free ends and clamped ends, respectively. For the clamped boundary condition, $E_{c 1}$ is defined as the energy absorbed when the midspan of the monolithic arch touches the base plate. $E_{f}$ and $E_{c 2}$ are defined as the energy absorbed when the displacement reaches $90 \%$ of the height of the arch.

Specific energy absorption (SEA), which is defined as the ratio of energy to the mass, is also listed in Table 5, where subscripts have the same meaning as the above. It was found that SEA $f$ was almost the same for free end arc-Miura models with different $a_{1}$ except for the case when $a_{1}=35.1 \mathrm{~mm}$. However, for the clamped arc-Miura, SEA decreased greatly with increasing $a_{1}$. With the increasing number of cells, $m$, SEA increased for both the boundary conditions. When $m=22, \mathrm{SEA}_{c 2}$ was five times as much as that when $m=10$.

For the monolithic arch, $\mathrm{SEA}_{f}$ and $\mathrm{SEA}_{c 1}$ remained almost the same for both the boundary conditions. For the monolithic arch, after the plastic hinge touched the bottom plate for the clamped condition, the force increased dramatically, and it would be meaningless to calculate the energy absorption afterwards. Generally, SEA of the arc-Miura is around 2-4 times as much 
as their corresponding monolithic arch for both the boundary conditions.

Table 5 Energy absorbed by different models

\begin{tabular}{|c|c|c|c|c|c|c|c|c|c|c|}
\hline & $\begin{array}{c}a_{1} \\
(\mathrm{~mm})\end{array}$ & $m$ & $\begin{array}{c}\text { Mass } \\
(\mathrm{kg})\end{array}$ & $\begin{array}{l}2 \gamma \\
\left({ }^{0}\right)\end{array}$ & $\begin{array}{l}E_{f} \\
(J)\end{array}$ & $\begin{array}{l}\mathrm{SEA}_{\mathrm{f}} \\
(\mathrm{J} / \mathrm{kg})\end{array}$ & $\begin{array}{l}E_{c 1} \\
(J)\end{array}$ & $\begin{array}{l}\mathrm{SEA}_{\mathrm{c} 1} \\
(\mathrm{~J} / \mathrm{kg})\end{array}$ & $\begin{array}{l}E_{c 2} \\
(J)\end{array}$ & $\begin{array}{c}\mathrm{SEA}_{\mathrm{c} 2} \\
(\mathrm{~J} / \mathrm{kg})\end{array}$ \\
\hline \multirow{7}{*}{$\begin{array}{l}\text { Arc- } \\
\text { Miura }\end{array}$} & 33.4 & \multirow{4}{*}{10} & \multirow{4}{*}{2.09} & \multirow{4}{*}{70} & 258.3 & 123.6 & 214.2 & 102.5 & 1060.0 & 507.2 \\
\hline & 33.9 & & & & 259.7 & 124.2 & 244.5 & 117.0 & 946.8 & 453.0 \\
\hline & 34.5 & & & & 223.2 & 106.8 & 123.4 & 59.0 & 360.5 & 172.5 \\
\hline & 35.1 & & & & 98.8 & 47.3 & 108.3 & 51.8 & 356.0 & 170.3 \\
\hline & & 14 & 2.93 & 98 & 283.2 & 96.7 & 411.3 & 140.4 & 1530.9 & 522.5 \\
\hline & 34.5 & 18 & 3.77 & 126 & 314.9 & 83.5 & 700.4 & 185.8 & 2787.6 & 739.4 \\
\hline & & 22 & 4.61 & 154 & 360.0 & 78.1 & 1130.5 & 245.2 & 3976.4 & 862.6 \\
\hline \multirow{4}{*}{$\begin{array}{l}\text { Mon- } \\
\text { olithic } \\
\text { arch }\end{array}$} & & & 2.09 & 70 & 51.6 & 24.7 & 130.2 & 62.3 & - & - \\
\hline & & & 2.93 & 98 & 67.5 & 23.0 & 190.6 & 65.1 & - & - \\
\hline & & & 3.77 & 126 & 87.2 & 23.1 & 251.3 & 66.7 & - & - \\
\hline & & & 4.61 & 154 & 107.5 & 23.3 & 318.3 & 69.0 & - & - \\
\hline
\end{tabular}

\section{Conclusions}

Arc-Miura specimens were successfully manufactured by stamping aluminium alloy sheets between a male and a female die. Quasi-static out-of-plane compressive tests on the manufactured arc-Miura specimens were conducted. Two boundary conditions were used: free ends and clamped ends. Force-displacement curves were obtained from the experiments, for two different boundary conditions.

FEA models of the arc-Miura were developed and validated with the experimental results. Parametric study of the mechanical properties of the arc-Miura models subjected to quasi-static out-of-plane compression was performed, and the deformation patterns were obtained. For the clamped ends, a necking effect appeared in the final deformation when the numbers of unit cells was large enough. The effects of geometric parameters on the mechanical properties of the arcMiura structure were investigated.

The arc-Miura models and corresponding monolithic arches were compared. The deformation patterns were almost the same for the two structures with free ends. For clamped ends, the monolithic arches had a stationary plastic hinge at midspan, while arc-Miura models with clamped ends did not have a plastic hinge. The energy absorbed by the two structures was 
compared. It was shown that arc-Miura structures perform better than the corresponding monolithic arches in terms of force and the energy absorption.

\section{Acknowledgements}

The authors wish to thank the Australian Research Council for the financial support through a Discovery Grant (DP160102612) and the National Natural Science Foundation of China under grant number 51578361. ZY acknowledges the support from the US Airforce Office of Scientific Research (FA9550-16-1-0339).

\section{References}

[1] Thrall AP, Quaglia CP. Accordion shelters: A historical review of origami-like deployable shelters developed by the US military. Engineering Structures. 2014;59:686-92.

[2] Quaglia CP, Dascanio AJ, Thrall AP. Bascule shelters: A novel erection strategy for origami-inspired deployable structures. Engineering Structures. 2014;75:276-87.

[3] Miura K. Zeta-core sandwich - Its concept and realization. Institution of Space and Aeronautical Science, University of Tokyo; 1972. p. 137-64.

[4] Zheng X, Lee H, Weisgraber TH, Shusteff M, DeOtte J, Duoss EB et al. Ultralight, ultrastiff mechanical metamaterials. Science. 2014;344:1373-7.

[5] Schenk M, Allwood J, Guest S. Cold gas-pressure folding of Miura-ori sheets. Proceedings of International Conference on Technology of Plasticity (ICTP)2011.

[6] Gattas JM, You Z. Design and digital fabrication of folded sandwich structures. Automation in Construction. 2016;63:79-87.

[7] Gattas JM, You Z. Geometric assembly of rigid-foldable morphing sandwich structures. Engineering Structures. 2015;94:149-59.

[8] Xie RK, Chen Y, Gattas JM. Parametrisation and application of cube and eggbox-type folded geometries. International Journal of Space Structures. 2015;30:99-110.

[9] Liu X, Gattas JM, Chen Y. One-DOF superimposed rigid origami with multiple states. Sci Rep. 2016;6:36883.

[10] Zhou X, Wang H, You Z. Mechanical properties of Miura-based folded cores under quasistatic loads. Thin-Walled Structures. 2014;82:296-310.

[11] Gattas JM, You Z. The behaviour of curved-crease foldcores under low-velocity impact loads. International Journal of Solids and Structures. 2015;53:80-91.

[12] Gattas JM, You Z. Quasi-static impact of indented foldcores. International Journal of Impact Engineering. 2014;73:15-29.

[13] Fathers RK, Gattas JM, You Z. Quasi-static crushing of eggbox, cube, and modified cube foldcore sandwich structures. International Journal of Mechanical Sciences. 2015;101-102:4218 .

[14] Liu S, Lu G, Chen Y, Leong YW. Deformation of the Miura-ori patterned sheet. International Journal of Mechanical Sciences. 2015;99:130-42. 
[15] Zang S, Zhou X, Wang H, You Z. Foldcores made of thermoplastic materials: Experimental study and finite element analysis. Thin-Walled Structures. 2016;100:170-9.

[16] Song J, Chen Y, Lu G. Axial crushing of thin-walled structures with origami patterns. Thin-Walled Structures. 2012;54:65-71.

[17] Yang K, Xu S, Shen J, Zhou S, Xie YM. Energy absorption of thin-walled tubes with prefolded origami patterns: Numerical simulation and experimental verification. Thin-Walled Structures. 2016;103:33-44.

[18] Eidini M. Zigzag-base folded sheet cellular mechanical metamaterials. Extreme Mechanics Letters. 2016;6:96-102.

[19] Zhou X, Zang S, Wang H, You Z. Geometric design and mechanical properties of cylindrical foldcore sandwich structures. Thin-Walled Structures. 2015;89:116-30.

[20] Schenk M, Guest S. Geometry of Miura-folded metamaterials. Proceedings of the National Academy of Sciences (PNAS). USA2013. p. 3276-81.

[21] Wei ZY, Guo ZV, Dudte L, Liang HY, Mahadevan L. Geometric mechanics of periodic pleated origami. Phys Rev Lett. 2013;110:215501.

[22] Lv C, Krishnaraju D, Konjevod G, Yu H, Jiang H. Origami based mechanical metamaterials. Sci Rep. 2014;4:5979.

[23] Kintscher M, Kärger L, Wetzel A, Hartung D. Stiffness and failure behaviour of folded sandwich cores under combined transverse shear and compression. Composites Part A: Applied Science and Manufacturing. 2007;38:1288-95.

[24] Kilchert S, Johnson AF, Voggenreiter H. Modelling the impact behaviour of sandwich structures with folded composite cores. Composites Part A: Applied Science and Manufacturing. 2014;57:16-26.

[25] Gattas JM, Wu W, You Z. Miura-base rigid origami: Parameterizations of first-level derivative and piecewise geometries. Journal of Mechanical Design. 2013;135:111011.

[26] Heimbs S. Virtual testing of sandwich core structures using dynamic finite element simulations. Computational Materials Science. 2009;45:205-16.

[27] Fischer S, Drechsler K, Kilchert S, Johnson A. Mechanical tests for foldcore base material properties. Composites Part A: Applied Science and Manufacturing. 2009;40:1941-52.

[28] Heimbs S, Cichosz J, Klaus M, Kilchert S, Johnson AF. Sandwich structures with textilereinforced composite foldcores under impact loads. Composite Structures. 2010;92:1485-97.

[29] Gattas JM. Quasi-static impact of foldcore sandwich panels: University of Oxford; 2013.

[30] Fischer S. Aluminium foldcores for sandwich structure application: Mechanical properties and FE-simulation. Thin-Walled Structures. 2015;90:31-41.

[31] Lu G, Yu TX. Energy absorption of structures and materials. 1st ed. Cambridge2003.

[32] Gill SS. Large deflection rigid plastic analysis of a built-in semi-circular arch. International Journal of Mechanical Engineering. 1976;4:339-55.

[33] Zhao GH, Liang Z, Tian JL, Jiang FG, Zhang L. Large deflection plastic studying on preforming of multilateral tool. Materials Research Innovations. 2013;15:s49-s52. 


\section{Appendix}

A. Theoretical analysis of a monolithic arch

(a) Monolithic arch with free ends

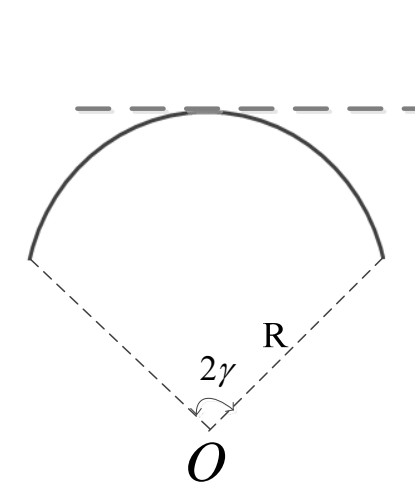

(a)

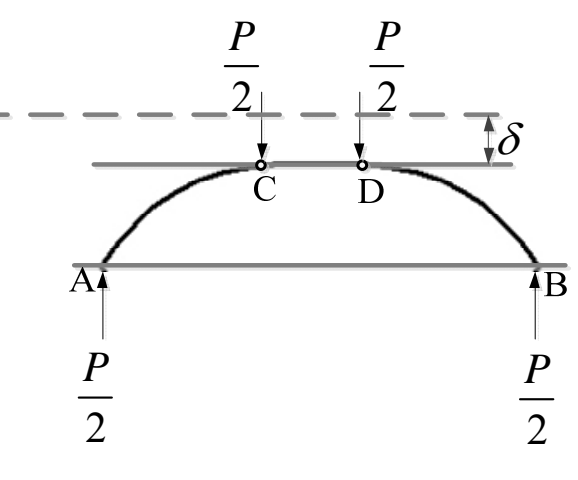

(b)

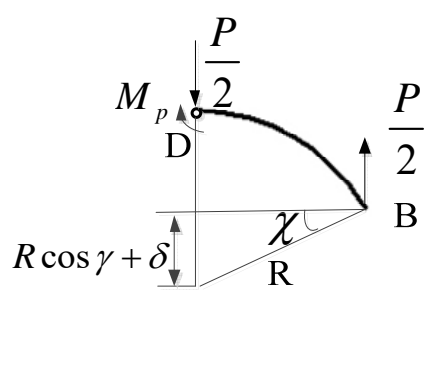

(c)

Fig. A1 Compression on an arch: (a) undeformed arch; b) collapse mechanism (c) forces on an undeformed segment.

A monolithic arch with an angle $2 \gamma$ is shown in Fig. A1 (a). For the free end condition, two plastic hinges (C and D in Fig. A1 (b)) are needed for a rigid-perfectly plastic arch to collapse under compression between two flat plates [31]. The force diagram for the undeformed segment is shown in Fig. A1 (c). The material is assumed rigid, perfectly plastic. From equilibrium,

$$
\frac{1}{2} P R \cos \chi=M_{p}
$$

and from geometry,

$$
R \cos \gamma+\delta=R \sin \chi
$$

The value of the angle $\chi$ changes with the increasing displacement. Combining Eq.(A1) with (A2), the variable $\chi$ can be eliminated, and the relationship between force $P$ and displacement $\delta$ is obtained, 


$$
P=2 M_{p} /\left\{R \cos \left[\arcsin \left(\cos \gamma+\frac{\delta}{R}\right)\right]\right\}
$$

where $M_{p}=\frac{t^{2} \sigma_{y} w_{u}}{4}$ is the fully plastic bending moment of the arch, $t$ is the thickness, $\sigma_{y}$ is the yield stress in simple tension, and $w_{u}$ is the width. This analytical relationship between the force and displacement is plotted as the dashed lines in Fig. 25, and they match well with the corresponding FEA results (see black line with black solid dots). The initial collapse force when $\delta=0$ decreases with increasing value of the arch angle $2 \gamma$.

(b) Monolithic arch with clamped ends

Consider a clamped monolithic arch compressed between two rigid plates (see Fig. A2). Let the initial collapse load be $P_{0} . P_{0}$ can be derived similarly to the case of an arch compressed by concentrated force [32]. Constrained force $P_{0}^{\prime}$ at fixed point B is in the direction of BC. The initial collapse load of built-in arch with an angle $2 \gamma$ can be obtained by mechanical analysis of arc ACB and arc EB. The expression for $P_{0}$ is [33]

$$
P_{0}=2 M_{p} \sin (\gamma / 2) /\left[R \sin ^{2}(\gamma / 4)\right]
$$

Here the effect of the axial force on yielding is ignored. This simplification is reasonable on the condition that the thickness is much less than the diameter and the transverse deformation is small [33]. The initial force $P_{0}$ is plotted as the solid blue lines in Fig. 25, which shows a good agreement with the corresponding FEA results (see red line with red solid dots). The initial force $P_{0}$ decreases with increasing arch angle $2 \gamma$. 


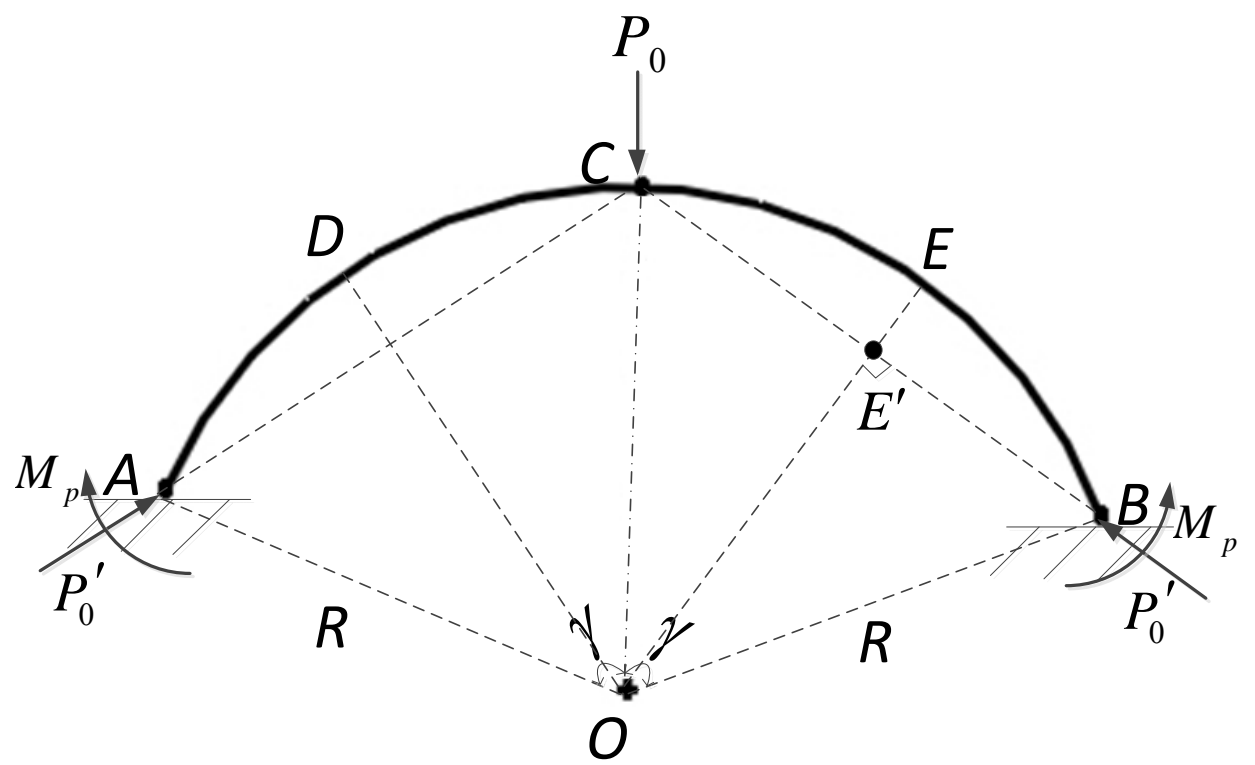

Fig. A2 Initial collapse mechanism of a clamped arch. 